\title{
The medium-/long-chain fatty acyl-CoA dehydrogenase (fadF) gene of Salmonella typhimurium is a phase 1 starvation-stress response (SSR) locus
}

\author{
Michael P. Spector, ${ }^{1}$ Concetta C. DiRusso, ${ }^{2}$ Mark J. Pallen, ${ }^{3} \dagger$ \\ Francisco Garcia del Portillo, ${ }_{\ddagger} \neq$ Gordon Dougan $^{3}$ and B. Brett Finlay ${ }^{4}$
} Author for correspondence: Michael P. Spector. Tel: +1 334380 2710. Fax: +1 3343802711.
e-mail: mspector@usamail.usouthal.edu

\author{
1 Department of Biomedical \\ Sciences, University of \\ South Alabama, Mobile, \\ AL 36688, USA \\ 2 Department of \\ Biochemistry and \\ Molecular Biology, The \\ Albany Medical College, \\ Albany, NY 12208, USA \\ ${ }^{3}$ Department of \\ Biochemistry, Imperial \\ College of Science, \\ Technology and Medicine, \\ London SW7 2AY, UK \\ 4 Biotechnology Laboratory \\ and Departments of \\ Biochemistry and \\ Microbiology, University of \\ British Columbia, \\ Vancouver, British \\ Columbia, Canada V6T 173
}

\begin{abstract}
Salmonella enterica serovar Typhimurium (S. typhimurium) is an enteric pathogen that causes significant morbidity in humans and other mammals. During their life cycle, salmonellae must survive frequent exposures to a variety of environmental stresses, e.g. carbon-source (C) starvation. The starvation-stress response (SSR) of S. typhimurium encompasses the genetic and physiological realignments that occur when an essential nutrient becomes limiting for bacterial growth. The function of the SSR is to produce a cell capable of surviving long-term starvation. This paper reports that three C-starvation-inducible lac fusions from an S. typhimurium C-starvationinducible lac fusion library are all within a gene identified as fadF, which encodes an acyl-CoA dehydrogenase (ACDH) specific for medium-/long-chain fatty acids. This identification is supported by several findings: (a) significant homology at the amino acid sequence level with the ACDH enzymes from other bacteria and eukaryotes, (b) undetectable $\beta$-oxidation levels in fadF insertion mutants, (c) inability of fad insertion mutants to grow on oleate or decanoate as a sole C-source, and (d) inducibility of fadF:: lac fusions by the long-chain fatty acid oleate. In addition, the results indicate that the $C$-starvation-induction of fadF is under negative control by the FadR global regulator and positive control by the CAMP: CAMP receptor protein complex and ppGpp. It is also shown that the fadF locus is important for C-starvationsurvival in S. typhimurium. Furthermore, the results demonstrate that fadF is induced within cultured Madin-Darby canine kidney (MDCK) epithelial cells, suggesting that signals for its induction (C-starvation and/or long-chain fatty acids) may be present in the intracellular environment encountered by S. typhimurium. However, fadF insertion mutations did not have an overt effect on mouse virulence.
\end{abstract}

Keywords: starvation-stress response, fatty acid degradation, fadR, cAMP-receptor protein, ppGpp

\footnotetext{
† Present address: Microbial Pathogenicity Research Group, Department of Medical Microbiology, St Bartholomew's and the Royal London School of Medicine and Dentistry, London EC1A 7BE, UK.

‡ Present address: Centro de Biologia Molecular 'Severo Ochoa', Universidad Autónoma de Madrid, 28049 Madrid, Spain.

Abbreviations: $A C D H$, acyl-COA dehydrogenase; LCACDH, medium- $/$ long-chain fatty acid specific ACDH; MDCK, Madin-Darby canine kidney; SP-PCR, single-primer polymerase chain reaction; SSR, starvation-stress response; CAMP:CRP, CAMP:CAMP receptor protein complex; TCA, tricarboxylic acid.
}

\section{INTRODUCTION}

Serovars of Salmonella enterica (e.g. S. enterica serovar Typhimurium or $S$. typhimurium) face a variety of potentially lethal stresses as they move between and within external and host microenvironments. Thus, it is imperative that salmonellae, and other enteric bacteria, are able to sense, respond to and adapt to changing environments in order to survive (Brown \& Williams, 1985; Babior, 1992; Foster \& Spector, 1995). A common 
stress encountered by S. typhimurium and other bacteria is starvation for an energy-yielding carbon (C) source (Koch, 1971; Harder \& Dijkhuizen, 1983; Roszak \& Colwell, 1987; Moriarty \& Bell, 1993). The changes in cellular physiology and gene expression that the organism undergoes in response first to limitation and then to starvation for an essential nutrient is referred to as the starvation-stress response (SSR) (Foster \& Spector, 1986; Spector et al., 1986, 1988; Spector, 1990; reviewed by Spector \& Foster, 1993; Spector, 1998). The function of the SSR is to allow the bacteria to survive periods of long-term starvation, since preventing its induction using protein synthesis inhibitors results in rapid loss of cultural viability. C-starvation is more effective at inducing long-term starvation-survival than are phosphate-source $(\mathrm{P})$ or nitrogen-source $(\mathrm{N})$ starvation (Spector \& Cubitt, 1992; Spector \& Foster, 1993; M. P. Spector, unpublished results). In addition, induction of the SSR as a result of C-starvation makes the cells more resistant to a number of other environmental stresses, e.g. presence of hydrogen peroxide, extremes in temperature, $\mathrm{pH}$ and osmolarity, and the presence of cationic antimicrobial peptides (Jenkins et al., 1988; Matin, 1991; Lange \& Hengge-Aronis, 1991; McCann et al., 1991; Fang et al., 1992; Seymour et al., 1996; McLeod \& Spector, 1996; M. P. Spector, unpublished results).

Using Mud-lac insertion techniques, a library of lac operon fusions to genetic loci induced during C-starvation has been identified in S. typhimurium. Characterization of some of the loci identified from this library (M. P. Spector, unpublished results) and from a previous library (Spector et al., 1988) has shown that gene induction in response to C-starvation occurs in a sequential manner, allowing the SSR to be divided into at least four phases, designated phase 0 through 3 , based on the sequential timing of their induction (Spector $\&$ Foster, 1993). Each phase can be subdivided temporally based upon whether genes are continually expressed or expressed only for defined periods of time. The majority of loci identified are phase 1 loci in that they are induced during the transition from growth to C-starvationinduced non-growth. Several phase 1 gene products are required for long-term starvation-survival, and are referred to as core SSR loci (Spector \& Cubitt, 1992). Not surprisingly, many, but not all, core SSR loci are under the control of the starvation/stress sigma factor encoded by the $r p o S$ gene, $\sigma^{\mathrm{S}}$ or $\sigma^{38}$ (Mulvey \& Loewen, 1989; Tanaka et al., 1993; O'Neal et al., 1994; for reviews see Hengge-Aronis, 1993, 1996; Loewen \& Hengge-Aronis, 1994; Spector, 1998).

Upon induction of the SSR, numerous structural and physiological changes in the cellular envelope occur in starved cells of both S. typhimurium and Escherichia coli. These include increased lipopolysaccharide in the outer membrane, a shift from phosphatidylglycerol to diphosphatidylglycerol (i.e. cardiolipin) in the inner membrane, and increased thickness and cross-linking of the peptidoglycan as well as expanded attachment of the murein layer to the outer membrane (reviewed by
Huisman et al., 1996). Another hallmark of starved cells is the decrease in the relative amounts of long-chain monounsaturated fatty acids, e.g. palmitoleic and cisvaccenic acids, in their inner membranes. This is due primarily to the direct conversion of unsaturated fatty acids to their cyclopropane derivatives by the membrane-bound cyclopropane fatty acid synthase encoded by the $c f a$ gene (Taylor \& Cronan, 1976; ElKhani \& Stretton, 1981). Interestingly, the $c f a$ locus is stationary-phase inducible and regulated by $\sigma^{\mathrm{s}}$. The importance of this shift is still unclear since strains unable to carry out this conversion do not appear to exhibit any discernible sensitivity to starvation or other environmental stresses (Taylor \& Cronan, 1976; reviewed by Cronan \& Rock, 1996). Concurrent with the shift in fatty acid composition of the cell's inner membrane is a reduction in size of starved cells compared to growing cells. This involves a shutting down of phospholipid synthesis and increased phospholipid turnover, indicating that during the initial stages of starvation monounsaturated fatty acids may provide Csources enabling the cell to mount an SSR and survive long-term starvation conditions. In particular, degradation of these fatty acids through $\beta$-oxidation would generate acetyl-CoA to feed the tricarboxylic acid (TCA) cycle, yielding C-compound intermediates and electron $/ \mathrm{H}^{+}$ion donors for energy production.

We describe here a phase $1 \mathrm{C}$-starvation-inducible locus, identified from a MudJ-generated lac fusion library, that partial DNA sequencing, biochemical and genetic analyses indicate encodes a medium-/long-chain fatty acylCoA dehydrogenase (LCACDH) required for $\beta$-oxidation of fatty acids. We have designated it fadF to reflect current nomenclature (Klein, 1973; Overath et al., 1969; reviewed by Black \& DiRusso, 1994; DiRusso \& Nyström, 1998). Furthermore, we report that Cstarvation-induction of this locus is under the control of the global regulators FadR and cAMP: cAMP receptor protein (cAMP:CRP) as well as the alarmone ppGpp. This is, to our knowledge, the first report of a fad gene being under the control of ppGpp. In addition, we demonstrate that this locus is induced within cultured Madin-Darby canine kidney (MDCK) epithelial cells, is important for $S$. typhimurium's survival during C-starvation, but does not appear to be needed for virulence in the mouse model.

\section{METHODS}

Bacterial strains, phage and transductions. The strains used in this study were all derivatives of the Salmonella enterica serovar Typhimurium (Salmonella typhimurium) strain SL1344 or TR6583 and are listed in Table 1. Transductions were performed using a high-transducing derivative of $S$. typhimurium bacteriophage P22, P22 HT 105/1 int (HT phage) (Chan et al., 1972). In all cases, transductants were determined to be non-lysogens for phage P22 by growth on Green indicator plates (Davis et al., 1980) and sensitivity to the H5 derivative of P22 (Maloy, 1990).

Culture media, supplements and antibiotics. The minimal media used in this study were either a modified MOPS- 
Table 1. S. typhimurium strains used in this study

\begin{tabular}{|c|c|c|}
\hline Strain & Genotype (pertinent phenotype) ${ }^{*}$ & Source/reference $†$ \\
\hline ST16 & Wild-type Salmonella typhimurium LT-2 (attenuated) & J. Foster \\
\hline TT10287 & hisD9953:: MudJ (lac Kan $\left.{ }^{\mathrm{R}}\right)$ his-9941::MudA (lac Amp $\left.{ }^{\mathrm{R}}\right)$ & J. Roth; Castilho et al. (1984) \\
\hline SL1344 & hisG46 (virulent Salmonella typhimurium) & Hoiseth \& Stocker (1981) \\
\hline ST50 & SL1344 fadF102 (csi-11)::MudJ $\left(\operatorname{lac} \mathrm{Kan}^{\mathrm{R}}\right)$ & This study \\
\hline ST54 & SL1344 fadF103 (csi-20)::MudJ $\left(\right.$ lac $\left.\mathrm{Kan}^{\mathrm{R}}\right)$ & This study \\
\hline ST64 & SL1344 fadF104 (csi-101)::MudJ $\left(\operatorname{lac} \mathrm{Kan}^{\mathrm{R}}\right)$ & This study \\
\hline SMS451 & ST54 crp-773:: Tn10 $\left(\right.$ Tet $\left.^{\mathrm{R}}\right)$ & This study; P. Postma \\
\hline SMS506 & ST54 cya: :Tn10 $\left(\right.$ Tet $\left.^{\mathrm{R}}\right)$ & This study; P. Postma \\
\hline SMS572 & SMS506 $c r p^{*}-771$ & This study; P. Postma \\
\hline SMS452 & ST54 rpoS: : $\Omega-$ Amp $^{\mathrm{R}}$ & This study; Fang et al. (1992) \\
\hline SMS505 & ST54 relA21:: Tn10 $\left(\right.$ Tet $\left.^{\mathrm{R}}\right)$ & This study; Rudd et al. (1985) \\
\hline SMS566 & ST54 spoT1 zhj-1036::Tn10 $\left(\right.$ Tet $\left.^{\mathrm{R}}\right)$ & This study; Rudd et al. (1985) \\
\hline SMS567 & ST54 spoT22 zhj-1036::Tn10 $\left(\right.$ Tet $\left.^{\mathrm{R}}\right)$ & This study; Rudd et al. (1985) \\
\hline SMS568 & ST54 spoT $T^{+} z h j-1036:: \operatorname{Tn} 10\left(\mathrm{Tet}^{\mathrm{R}}\right)$ & This study; Rudd et al. (1985) \\
\hline SMS569 & ST54 $\Delta$ relA spoT1 zhj-1036:: Tn10 $\left(\mathrm{Tet}^{\mathrm{R}}\right)$ & This study; Rudd et al. (1985) \\
\hline SMS570 & ST54 $\Delta$ relA spoT22 zhj-1036:: Tn10 $\left(\right.$ Tet $\left.^{\mathrm{R}}\right)$ & This study; Rudd et al. (1985) \\
\hline SMS571 & ST54 $\Delta$ relA spo $T^{+} z h j-1036:: \operatorname{Tn} 10\left(\mathrm{Tet}^{\mathrm{R}}\right)$ & This study; Rudd et al. (1985) \\
\hline TR6583 & LT-2 metE205 ara-9 & C. C. DiRusso \\
\hline SMS645 & TR6583 fadF103:: MudJ $\left(\operatorname{lac} \mathrm{Kan}^{\mathrm{R}}\right)$ & This study \\
\hline LS1860 & TR6583 fadR101 & This study \\
\hline SMS648 & LS1860 fadF103::MudJ $\left(\operatorname{lac} \mathrm{Kan}^{\mathrm{R}}\right)$ & This study \\
\hline
\end{tabular}

${ }^{*} \mathrm{Kan}^{\mathrm{R}}$, kanamycin resistance; $\mathrm{Amp}^{\mathrm{R}}$, ampicillin resistance; $\mathrm{Tet}^{\mathrm{R}}$, tetracycline resistance

†J. Foster, University of South Alabama; J. Roth, University of Utah; P. Postma, University of Amsterdam.

buffered salts (MS)-based medium (Neidhardt et al., 1974; described in detail by Spector et al., 1988; Spector \& Cubitt, 1992) or an NCE-based medium (Davis et al., 1980). MS medium nonlimiting in glucose, phosphate and nitrogen (MS hiPCN) was used to generate exponential-phase cells, while MS medium with $0.03 \%(\mathrm{w} / \mathrm{v})$ glucose (MS loC) was used to generate C-starved cells. The rich media used were Luria (L) or Luria-Bertani (LB) agar and broth (Davis et al., 1980; Difco) and tryptone broth (TB) (Miller, 1972; Difco).

Histidine and methionine were added, as needed, to a final concentration of $0.2 \mathrm{mM}$ and $0.3 \mathrm{mM}$, respectively. Decanoate and oleate (Sigma) were each used at final concentrations of $5 \mathrm{mM}$ or $1 \mathrm{mM}$, as needed. Brij 58 (Sigma) was used to solubilize free fatty acids at a final concentration of $0.5 \%$ $(\mathrm{v} / \mathrm{v})$. Kanamycin (Kan), ampicillin (Amp) and tetracycline (Tet) were used, as needed, at a final concentration of $100 \mu \mathrm{g}$ $\mathrm{ml}^{-1}, 50 \mu \mathrm{g} \mathrm{ml}^{-1}$ and $10 \mu \mathrm{g} \mathrm{ml}^{-1}$ (minimal) or $20 \mu \mathrm{g} \mathrm{ml}^{-1}$ (rich), respectively, X-Gal was used, as an indicator of $\beta$ galactosidase activity (encoded by lacZ), in solid media at a final concentration of $40 \mu \mathrm{g} \mathrm{ml}^{-1}$.

Strains carrying $c y a, c r p$ or $c r p *$ mutations were grown on MacConkey's $0.5 \%(\mathrm{w} / \mathrm{v}$ ) mannitol (Difco) agar plates, plus the appropriate antibiotics as needed, to confirm the correct phenotype (Saier et al., 1996) of the strains prior to being tested. Phenotypes of relA, spoT or relA spoT double mutants were confirmed as described by Rudd et al. (1985) prior to being tested. Strains carrying an $r p o S$ knockout mutation were confirmed as previously described (O'Neal et al., 1994), again, prior to being tested.

Construction of the csi::lac fusion strain library. A his $^{+}$ kanamycin (Kan)-sensitive S. typhimurium LT-2 strain (ST16) was transduced with HT phage propagated on strain TT10287 selecting for Kan resistance $\left(\mathrm{Kan}^{\mathrm{R}}\right)$ on LB Kan agar plates (Castilho et al., 1984; Hughes \& Roth, 1988). Kan ${ }^{\mathrm{R}}$ transductants were then replica-plated onto nonlimiting minimal agar medium (MS hiPCN) and glucose (C)-limiting minimal agar medium (MS loC) supplemented with Kan and X-Gal. These media allow for the selection of his $^{+} \mathrm{Kan}^{\mathrm{R}}$ transductants, indicating that they acquired $\mathrm{Kan}^{\mathrm{R}}$ as a result of transposition of the MudJ (lac $\mathrm{Kan}^{\mathbf{R}}$ ) into a different site on the bacterial chromosome, as opposed to homologous recombination at the his locus, site in which the MudJ is inserted in strain TT10287 (Hughes \& Roth, 1988). $\mathrm{Kan}^{\mathrm{R}}$ his $^{+}$colonies that appeared more intensely blue on the limiting glucose medium compared to the nonlimiting glucose medium were selected for further study. The C-starvation-inducible (csi) phenotype of each fusion strain was confirmed by restreaking onto minimal nonlimiting and limiting glucose X-Gal Kan agar plates (Spector et al., 1988; Spector \& Cubitt, 1992). The collection of $c s i:$ :lac-containing strains was then catalogued and stored at $-70^{\circ} \mathrm{C}$.

Single-primer polymerase chain reaction (SP-PCR) amplification, analysis and DNA sequencing of $S$. typhimurium DNA flanking each Muds insertion site. An adaptation of the SP-PCR method of Parks et al. (1991) was used to amplify chromosomal DNA adjacent to the MudJ insertion sites of $c s i$ $11, c s i-20$ and $c s i-101$. This method relies on the use of a single PCR primer designed to prime DNA synthesis out of the region of known sequence. For this, a 25 nt oligomer ( 25 -mer) complementary to sequences in the left end of $\mathrm{Mud}(\mathrm{MudL}$; GenBank accession no. M10190) and that primes DNA synthesis out of the MudJ into adjacent chromosomal DNA was synthesized and used as a primer (PMudL; $5^{\prime}$ ATC CCG AAT AAT CCA ATG TCC TCC C 3'). Although exponential amplification of the $\mathrm{MudJ} /$ chromosome boundary can only 
occur if the primer also binds to a stretch of partial sequence complementarity in the region of unknown sequence on the opposite strand, this occurs at a sufficient frequency so as to be useful, if one or more of the PCR cycles includes a low annealing temperature. If successful, this primer should yield a product possessing $34 \mathrm{bp}$, nested between the primer-binding site and the end of the MudL sequence, at one of its ends. Products not containing this $34 \mathrm{bp}$ region were considered artifacts of the procedure and not studied further.

SP-PCR was performed on cell lysates from ST50, ST54, ST64 and wild-type parent SL1344. Lysates were prepared by suspending two or three medium-sized colonies, grown overnight on $\mathrm{L}$ agar, in $500 \mu \mathrm{l}$ sterile distilled water, heating at $99^{\circ} \mathrm{C}$ for $10 \mathrm{~min}$, and collecting the supernatant after centrifuging at maximum speed in a bench-top microfuge for $2 \mathrm{~min}$. Two microlitres of the supernatant was added to 6 pmol primer and the PCR reagents (Taq polymerase, buffer, and dNTPs) to a final volume of $50 \mu \mathrm{l}$.

The SP-PCR reactions were performed in an Omnigene thermal cycler (Hybaid), using a three-stage protocol. The first stage consisted of one cycle of $2 \mathrm{~min}$ at $96^{\circ} \mathrm{C}$ to ensure complete denaturation of the target DNA, followed by 20 cycles of $30 \mathrm{~s}$ at $94^{\circ} \mathrm{C}, 30 \mathrm{~s}$ at $50^{\circ} \mathrm{C}$ and 2 min at $72^{\circ} \mathrm{C}$, with the aim of creating multiple single-stranded copies of the $\mathrm{MudJ} /$ chromosome junction region through a specific but linear amplification reaction. The second stage included two cycles with a low annealing temperature and a slow ramp up to the optimum extension temperature (two cycles of $30 \mathrm{~s}$ at $94^{\circ} \mathrm{C}, 15 \mathrm{~s}$ at $30^{\circ} \mathrm{C}, 15 \mathrm{~s}$ at $35^{\circ} \mathrm{C}, 15 \mathrm{~s}$ at $40^{\circ} \mathrm{C}, 15 \mathrm{~s}$ at $45^{\circ} \mathrm{C}$, $15 \mathrm{~s}$ at $50^{\circ} \mathrm{C}, 15 \mathrm{~s}$ at $55^{\circ} \mathrm{C}, 15 \mathrm{~s}$ at $60^{\circ} \mathrm{C}, 15 \mathrm{~s}$ at $65^{\circ} \mathrm{C}, 2 \mathrm{~min}$ at $72{ }^{\circ} \mathrm{C}$ ) in order to encourage quasi-specific primer binding to chromosomal DNA close to the junction region, with subsequent primer extension creating a template bounded at both ends with primer-derived sequence. The third stage was a conventional PCR, aimed at exponential amplification of the template created in stage two, consisting of 30 cycles of $30 \mathrm{~s}$ at $94^{\circ} \mathrm{C}, 30 \mathrm{~s}$ at $50^{\circ} \mathrm{C}, 2 \mathrm{~min}$ at $72{ }^{\circ} \mathrm{C}$, followed by a final $5 \mathrm{~min}$ extension at $72^{\circ} \mathrm{C}$. Five-microlitre samples from each completed SP-PCR were analysed by TBE $/ 1 \%(\mathrm{w} / \mathrm{v})$ agarose gel electrophoresis, to confirm that each mutant yielded a product profile distinct from that of the wild-type parent (data not shown).

The DNA in the remaining $45 \mu \mathrm{l}$ of each SP-PCR was then ethanol-precipitated, resuspended and ligated to the pGEM-T plasmid and transformed into hyper-competent Escherichia coli HB101 cells (supplied with the vector) according to the manufacturer's instructions (Promega). Transformed cells were then inoculated onto LB Amp IPTG X-Gal plates and incubated overnight at $37^{\circ} \mathrm{C}$ according to the manufacturer's protocols. White colonies containing vector with insert were subcultured and analysed via PCR using forward and reverse vector-specific primers (Promega). Five-microlitre aliquots of the completed reactions were run on a TBE $/ 1 \%(\mathrm{w} / \mathrm{v})$ agarose gel to determine the presence and size of any insert.

A selection of amplified inserts (six from ST50 and six from ST54) were PEG-precipitated (Rosenthal et al., 1993), and then sequenced by Taq cycle sequencing using forward and/or reverse primers with subsequent analysis on an ABI 377 automated sequencer (Applied Biosystems). Again, sequences representing the MudJ/chromosome junctions (two from ST50 and three from ST54) were distinguished from sequences amplified non-specifically from elsewhere in the chromosome by the presence of the 34 bp of sequence derived from the end of the MudJ but not present in the SP-PCR primer PMudL. The locations of the MudJ insertions in ST50 and ST54 were subsequently confirmed by conventional specific PCRs using primers binding to the MudJ and to the sequenced chromosomal DNA (data not shown).

In the case of inserts amplified from the ST64 chromosome, an additional selective procedure was used before sequencing. A pair of overlapping divergent PCR primers (PMudLfor, 5' GGT CTA GAC ACT TGA AGT ACG AAA AAA ACC 3', and PMudLrev, 5' GGT CTA GAT TCA AGT GAA TCA ATA CA $3^{\prime}$ ) binding to sites in the 34 bp stretch between the PMudL binding site and the left end of the MudJ were used to screen white colonies. With this procedure, only colonies containing an amplified junction region yielded a PCR product, which consisted of the entire insert and vector combined (inverse PCR). One such PCR product was PEGprecipitated, then sequenced with primer PMudLrev. As the 3' end of this primer corresponds exactly to the leftmost end of the $\mathrm{MudJ}$ and it was impossible to be certain quite how close to the primer the resulting sequence began, the insertion site for the MudJ in ST64 [fadF104 (csi-101)::lac] could not be located precisely, but only to within a few base pairs.

Analysis of fad mutant growth phenotypes. To determine if the various MudJ insertion mutants could utilize oleate as a sole C-source, the appropriate strains (see Table 2) were inoculated onto NCE agar medium supplemented with $0.5 \%$ $(\mathrm{v} / \mathrm{v})$ Brij 58 and $0.3 \%(\mathrm{w} / \mathrm{v})$ glucose, $0.4 \%(\mathrm{w} / \mathrm{v})$ acetate or $5 \mathrm{mM}$ oleate as the sole C-sources. Agar plates were incubated at $37^{\circ} \mathrm{C}$ for up to $48 \mathrm{~h}$. The presence of growth was examined for after 18,24 and $48 \mathrm{~h}$.

Isolation and identification of a fadR mutant strain. Spontaneous fadR mutants of $S$. typhimurium TR6583 were isolated by heavily inoculating NCE agar medium containing $5 \mathrm{mM}$ decanoate and $0.5 \%(\mathrm{v} / \mathrm{v})$ Brij 58 with strain TR6583. Colonies that appeared on decanoate plates after $24 \mathrm{~h}$ were selected (longer incubations gave high background growth). Isolates were confirmed by restreaking onto NCE decanoate agar to demonstrate utilization of decanoate as a sole carbon and energy source. Positive isolates were also assayed to show constitutive levels of $\beta$-oxidation activity (see below), characteristic of fadR mutants. In addition, the mutation, designated fadR101, was confirmed by demonstrating suppression of growth on NCE decanoate agar and induction of wild-type $\beta$ oxidation levels by long-chain fatty acids following introduction, via electroporation, of a plasmid (pCG101) carrying the wild-type fadR gene of E. coli (DiRusso et al., 1992).

Assay for $\boldsymbol{\beta}$-oxidation activity. Bacterial cells were grown overnight in tryptone broth (TB) at $37^{\circ} \mathrm{C}$ with shaking. The overnight culture was then diluted $1: 100$ into $20 \mathrm{ml}$ fresh TB or $\mathrm{TB}$ plus $1 \mathrm{mM}$ oleate and $0.5 \%(\mathrm{v} / \mathrm{v})$ Brij 58 (TBO). Cultures were incubated at $37{ }^{\circ} \mathrm{C}$ with shaking and growth was monitored using a Klett-Summerson colorimeter equipped with a blue filter. At mid-exponential phase $\left(\mathrm{OD}_{600}\right.$ $\sim 0 \cdot 4-0 \cdot 5$ ), the culture was placed on ice for $10 \mathrm{~min}$, pelleted by centrifugation, and the cell pellet resuspended in $5 \mathrm{ml} \mathrm{NCE}$ containing $0.5 \%$ Brij 58 . Centrifugation was repeated and the cells were washed two additional times with NCE alone. After the last wash, cells were resuspended to an $\mathrm{OD}_{600}$ of $\sim 1.0$ in NCE containing $0.01 \%$ chloramphenicol. Fatty acid oxidation was assayed in whole cells by determining the amount of $\mathrm{CO}_{2}$ released from $\left[1-{ }^{14} \mathrm{C}\right]$ oleate $\left[50 \mathrm{mCi} \mathrm{mmol}{ }^{-1}\left(1.85 \times 10^{9} \mathrm{~Bq}\right.\right.$ $\left.\mathrm{mmol}^{-1}\right)$; Dupont NEN] as follows. Reaction mixtures contained $2 \mathrm{ml}$ cells and $100 \mathrm{nmol}\left[1{ }^{14} \mathrm{C}\right]$ oleate (50000 c.p.m.) in a $25 \mathrm{ml}$ Erlenmeyer flask equipped with a centre well (Kontes Glass Co.) and sealed with a rubber stopper. Triplicate samples were incubated at $30^{\circ} \mathrm{C}$ with gentle rotation (100 r.p.m.). After $60 \mathrm{~min}, 0.2 \mathrm{ml}$ ethanolamine 
(diluted 1:1 with ethanol) was added to the centre well and $0.5 \mathrm{ml} 2.5 \mathrm{M} \mathrm{H}_{2} \mathrm{SO}_{4}$ was added to the culture medium to release dissolved $\mathrm{CO}_{2}$. Incubation was continued for an additional $60 \mathrm{~min}$ then the centre well was removed and placed in a vial with $4 \mathrm{ml}$ scintillation fluor. Radioactivity was measured in a Beckman scintillation counter. Specific activity was calculated from the mean of three experiments and was expressed as $\mathrm{nmol}^{14} \mathrm{CO}_{2} \mathrm{~min}^{-1}$ (mg protein) ${ }^{-1}$.

C-starvation/oleate induction and $\beta$-galactosidase activity assay. C-starvation-induction of the various Mud-lac fusions was quantified in vitro by measuring $\beta$-galactosidase activity in exponential-phase cells and $3 \mathrm{~h} \mathrm{C}$-starved cells. For this, the desired strains were grown overnight in MS hiPCN broth, with antibiotic as needed, at $37^{\circ} \mathrm{C}$ with shaking. Overnight cultures were then diluted 1:100 into $4 \mathrm{ml}$ fresh MS hiPCN and MS loC media and incubated at $37^{\circ} \mathrm{C}$ with shaking. Growth was monitored by measuring $\mathrm{OD}_{600}$. Cells were grown to exponential phase in MS hiPCN broth $\left(\mathrm{OD}_{600}\right.$ $\sim 0.3-0.4)$ and assayed for $\beta$-galactosidase activity. Threehour C-starved cells were obtained by growing the cells in MS loC broth until growth stopped as a result of exhaustion of glucose and continuing to starve the cells for a total of $3 \mathrm{~h}$, at which point cells were assayed for $\beta$-galactosidase activity. $\beta$-Galactosidase activity was measured by the method of Miller (1972, 1992) and is expressed in Miller units.

To measure oleate induction of the various Mud-lac fusions, desired strains were grown overnight in TB broth plus antibiotic as needed at $37^{\circ} \mathrm{C}$ with shaking. Overnight cultures were then diluted $1: 100$ into $4 \mathrm{ml}$ fresh TB or TBO $(1 \mathrm{mM}$ oleate $/ 0.5 \%$ Brij 58 ). Cultures were incubated at $37^{\circ} \mathrm{C}$ with shaking and growth was monitored as above. Exponentialphase cells $\left(\mathrm{OD}_{600} \sim 0.3-0.4\right)$ in both media were then assayed for $\beta$-galactosidase activity. Again, $\beta$-galactosidase activity was measured by the method of Miller $(1972,1992)$ and is expressed in Miller units.

Assay for expression in MDCK epithelial cells. Infection and assay for intracellular $\beta$-galactosidase expression was carried out as previously described (Finlay \& Falkow, 1989; Garcia del Portillo et al., 1992). Briefly, MDCK epithelial cells (ATCC CCL 34) were grown to confluency in MEM medium containing $5 \%(\mathrm{v} / \mathrm{v})$ foetal bovine serum (FBS) in 96-well plates (approx. $10^{5}$ cells per well). Monolayers were infected with about $10^{6}$ bacteria, previously grown overnight in LB broth at $37^{\circ} \mathrm{C}$ without shaking. Bacterial infection was performed for $2 \mathrm{~h}$ at $37^{\circ} \mathrm{C}$. Infected epithelial cells were washed three times with phosphate-buffered saline (PBS) $\mathrm{pH} 7 \cdot 4$ to remove non-adherent bacteria. Infected monolayers were then incubated in the presence of fresh MEM plus $5 \%$ $(\mathrm{v} / \mathrm{v})$ FBS medium containing $100 \mu \mathrm{g}$ gentamicin $\mathrm{ml}^{-1}$, to kill any adherent non-internalized bacteria associated with the cell monolayer. Incubation with gentamicin was carried out for the period of $2-4 \mathrm{~h}$ post-infection. The gentamicin concentration was then reduced to $10 \mu \mathrm{g} \mathrm{ml}^{-1}$ and the monolayers were incubated for an additional $2 \mathrm{~h}(4-6 \mathrm{~h}$ post-infection). At $6 \mathrm{~h}$ post-infection, the MDCK monolayers were lysed with $1 \%(\mathrm{v} / \mathrm{v})$ Triton $\mathrm{X}-100$ in PBS $(\mathrm{pH} 7 \cdot 4)$ to release the intracellular bacteria. Viable cell counts were determined for the intracellular bacteria.

A cell lysate was also prepared to measure $\beta$-galactosidase activity in intracellular bacteria. Bacterial cells were lysed with $0.1 \%(\mathrm{w} / \mathrm{v})$ SDS and chloroform and $\beta$-galactosidase activity was measured using the fluorescent substrate fluorescein $\mathrm{di}-\beta$ D-thiogalactopyranoside (FDG) as previously described (Garcia del Portillo et al., 1992).
In addition, $\beta$-galactosidase activity was measured in parallelrun uninfected epithelial cells, and subtracted as the background. Extracellular (non-internalized) bacteria after $2 \mathrm{~h}$ incubation with MDCK monolayers were also collected, viable cell counts determined, and $\beta$-galactosidase activity measured for comparison with intracellular expression. Intracellular induction was expressed as the ratio between $\beta$-galactosidase activity in internalized bacteria and extracellular bacteria.

Virulence assays. Cultures of the Salmonella strains to be tested were grown overnight in $\mathrm{L}$ broth at $37^{\circ} \mathrm{C}$ without shaking. Cultures were pelleted by centrifugation at 4000 r.p.m. in a bench-top centrifuge. The cells were then resuspended in PBS. The $\mathrm{OD}_{650}$ was adjusted to 0.93 , which equates to a cell density of approximately $5 \times 10^{8}$ cells $\mathrm{ml}^{-1}$. For the $\mathrm{LD}_{50}$ determinations, serial dilutions were then made in PBS. Bacterial suspensions were administered intragastrically to 6-8-week-old female BALB/c mice by oral gavage in a volume of $200 \mu \mathrm{l}$. Mice were observed at least daily for the duration of the experiments.

C-starvation-survival assay. Long-term starvation-survival was assayed as previously described (Spector \& Cubitt, 1992; O'Neal et al., 1994) with the exception that cells were starved only for glucose. Briefly, desired strains were grown overnight in MS hiPCN broth plus antibiotics, as needed, at $37^{\circ} \mathrm{C}$ with shaking. Overnight cultures were diluted 1:100 into $4 \mathrm{ml}$ fresh MS hiPCN medium with antibiotics, as needed. Cells were grown at $37^{\circ} \mathrm{C}$ with shaking to exponential phase $\left(\mathrm{OD}_{600}\right.$ $\sim 0 \cdot 3-0 \cdot 4$ ) to dilute out, by exponential growth, any stress proteins produced during overnight growth. One millilitre of each exponential-phase culture was then mixed with $9 \mathrm{ml}$ fresh MS medium with nonlimiting P- and N-source but no Csource, plus antibiotics, as needed, in a $125 \mathrm{ml}$ screw-cap Erlenmeyer flask. The only C-source provided was that carried over from the exponential-phase culture: enough to support an additional two to three doublings and allow the bacteria to pass through a transition period from growth to stationary phase due to C-source exhaustion (O'Neal et al., 1994). At specified time intervals, aliquots of the culture were removed, serially diluted in MS buffer (MS medium without a C-, P- and $\mathrm{N}$-source), and plated onto LB agar, plus antibiotics as needed, to determine viable plate counts. Time zero was the point at which the culture stopped growing as a result of glucose exhaustion and entered C-starvation-elicited stationary phase. Percentage survival was calculated as c.f.u. $\mathrm{ml}^{-1}$ at each time point divided by the maximum c.f.u. $\mathrm{ml}^{-1}$ achieved (typically approx. $3-5 \times 10^{8}$ c.f.u. $\mathrm{ml}^{-1}$ ) multiplied by 100 .

\section{RESULTS}

\section{Identification of carbon starvation-stress response loci}

A Kan ${ }^{\mathrm{S}}$ his $^{+}$S. typhimurium LT-2 wild-type strain was transduced with a lysate of HT phage propagated on strain TT10287 selecting for kanamycin resistance on LB Kan agar plates. A total of approximately 60000 $\mathrm{Kan}^{\mathrm{R}}$ transductants were obtained and replica-plated onto nonlimiting MS hiPCN and glucose-limiting MS loC agar media supplemented with Kan and X-Gal but no histidine. $\mathrm{Kan}^{\mathrm{R}}$ his $^{+}$colonies that appeared more intensely blue on the limiting glucose medium compared to the nonlimiting glucose medium were selected for further characterization. From this search, and a pre- 
(a)

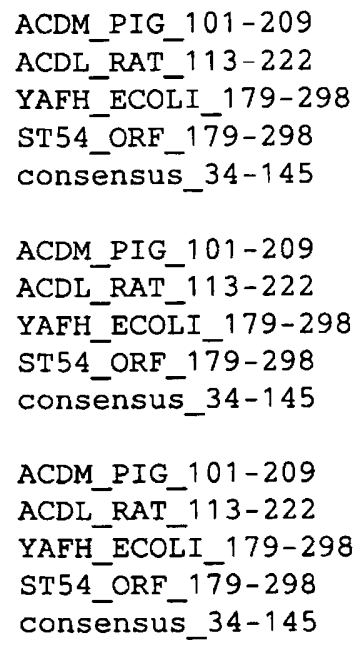

(b)

ACDM PIG 234-277

ACDL_RAT_246-289

YAFH_ECOLI_ $325-370$

ST64_ORF_325-370

consensus_170-213
GI IDSCLITEEL AYGCTGVQTA IEAN.TLGQV PLII.GGNYQ QQKKYLGRMT
DL LSTAVTWEEQ AYSNCT.GPG FSLHSDIVMP YIAN.YGTKE QIEQFIPQMT
SA YAQSRVLQRL SGVSGILAIT VGVPNSLGPG ELLQHYGTDE QKDHYLPRLA
SA YAQSRVLQKL SGVSGILAIT VGVPNSLGPG ELLQHYGTEE QKDHYLPRLA
DY VSYALVVEEL ARVDASVGVT MGVHNSLCMN PILQ.YGSEE QKEKYLPQLA

EEPLMCAYCV TEPGAGSDVA GIKTKAE... ...KKG.DE. YIINGQKMWI

AGKCIGAIAM TEPGAGSDLQ GVRTNAK... ...RSGSD.. WILNGSKVFI

RGQEIPCFAL TSPEAGSDAG AIPDTGIVCM GEWQGQQVLG MRLTWNKRYI RGQEIPCFAL TSPEAGSDAG AIPDTGVVCM GEWQGQQVLG MRLTWNKRYI KGEKIGCFAL TEPNAGSDVG SMKTRAE......KKGSDGS YVLNGSKMWI

TNGGKANWY. FLLARSDP

TNGWLSDLV. IVVAVTNR

TLAPIATVLG LAFKLSDP

TLAPIATVLG LAFKLSDS

TNGPVADVY. IVFARTDP

\begin{abstract}
GRKEIN MGQRCSDTRG IVFEDVRVPK ENVLTGE... GAGFKIAMGT F GKKLHK MGMKAQDTAE LFFEDVRLPA SALLGEE... NKGFYYLMQE L GRRHFP LNVPFQN.GP TRGKDVFVPI DYIIGGPKMA GQGWRMLVEC L GRRHFP LNVPSQN.GP TRGNDIFVPI DYIIGGPKMA GQGWRMLVEC I GKKEDK LGLRASDTCE IVFEDVRVPA ENILGEE... GEGFKVAMKT I
\end{abstract}

\section{(c)}

YAFH_ECOLI_547-642 ST50_ORF_5 $\overline{4} 7-642$

YAFH ECOLI $547-642$ ST50 ORF_5 $5 \overline{4} 7-642$

\begin{abstract}
GSNKVRSF WLGLTRGLTS STPTGDATKR YYQHLNRLSA NLALLSDVSM GSNTVRSF WLGLTRGLTS HTPTGDATKR YYQHLNRLSA NLALLSDVSM
\end{abstract}

\author{
AVLGGSLKRR ERISARLGDI LSQLYLASAV LKRYDDEGRN EADLPLVH \\ AVLGGSLKRR ERIFASLGDV LSQLYLASAV LKRYDDEGRH EADLPLVH
}

Fig. 1. Comparison between the primary sequences of mammalian medium- and long-chain $A C D H$ enzymes and the $E$. coli and S. typhimurium YafH (FadF). (a) Comparison of the primary sequences of a pig medium-chain ACDH (amino acids 101 through 209; ACDM_PIG_101-209), a rat long-chain ACDH (amino acids 113 through 222; ACDL_RAT_113-222), E. coli YafH ORF (amino acids 179 through 298; YAFH_ECOLI_179-298) and consensus ACDH sequence amino acids 34 through 145 (consensus_34-145) with that deduced from the sequence adjacent to the MudJ insertion in ST54 (ST54_ORF_179-298). (b) Comparison of the pig medium-chain ACDH (amino acids 234-277), rat long-chain ACDH (amino acids 246-289), E. coli YafH ORF (amino acids 325-370) and consensus ACDH sequence (amino acids 170-213) with that deduced from the sequence adjacent to the MudJ insertion in ST64 (ST64_ORF_325-370). (c) comparison of the E. coli YafH ORF (amino acids 547-642) with that deduced from the sequence adjacent to the MudJ insertion in ST50 (ST50_ORF_547-642). Bold letters indicate residues sharing identity with the $S$. typhimurium YafH ORF. Note that the insertion site for fadF104::MudJ-lac was determined using a primer whose $3^{\prime}$ end lies at the end of the Muds sequence. Uncertainties in how close to the primer the readable sequence began mean that the insertion site was not identified precisely, but it must lie at or within a few bases of nucleotide 970 or around amino acid 324 in E. coli YafH ORF. All sequences were obtained from the ProDom Database, release 34.2, acyl-CoA dehydrogenase domain.

vious search (Spector et al., 1988), a total of 76 independently isolated strains carrying C-starvationinducible lac fusions (csi::lac) were identified and maintained as a C-starvation-inducible lac fusion library. This library represents a collection of strains carrying independent csi::lac fusions around the $S$. typhimurium chromosome. Based on locations of different insertion sites identified to date, we estimate (a) about $25-30 \%$ redundancy (insertions in the same genetic locus but at different sites) and (b) that the library represents around 40-50 different C-starvationinducible genetic loci (Spector, 1998). Three of the csi: : lac fusions from this library, designated csi-11, csi20 and $c s i-101$, were transduced into the S. typhimurium SL1344 background for further characterization in this study. 
Table 2. Growth phenotypes of pertinent $S$. typhimurium strains on solid NCE minimal medium with different carbon sources

\begin{tabular}{|c|c|c|c|c|c|}
\hline \multirow[t]{2}{*}{ Strain $(s)$} & \multirow[t]{2}{*}{ Pertinent genotype } & \multicolumn{4}{|c|}{ Growth on indicated carbon source ${ }^{*}$ : } \\
\hline & & Glucose & Acetate & Oleate & Decanoate $\nmid$ \\
\hline TR6583/SL1344 & $\mathrm{fadR}^{+} \mathrm{fadF}^{+}$ & + & + & + & - \\
\hline ST50 & fadR $R^{+}$fadF102::lac & + & + & - & - \\
\hline SMS645/ST54 & $\mathrm{fadR}^{+}$fadF103::lac & + & + & - & - \\
\hline ST64 & fadR $R^{+}$fadF104::lac & + & + & - & - \\
\hline LS1860 & $\mathrm{fadR} 101 \mathrm{fadF}^{+}$ & + & + & + & + \\
\hline SMS648 & fadR101 fadF103::lac & + & + & - & - \\
\hline
\end{tabular}

$*+$, Growth on carbon source at $24 \mathrm{~h} ;-$, no growth on carbon source at $24 \mathrm{~h}$.

† Growth on decanoate-containing agar plates appeared after $48 \mathrm{~h}$ at $37^{\circ} \mathrm{C}$.

\section{Sequence analysis of chromosomal DNA adjacent to the MudJ insertion site in csi-11, csi- 20 and csi-101 indicates that all are in the same locus, yafH, but at different sites}

Chromosomal DNA adjacent to the MudJ insertion sites for $c s i-11, c s i-20$ and $c s i-101$, was amplified using an SP-PCR protocol and the DNA sequence was determined. Sequence for approximately 290,400 and 140 bp of DNA adjacent to the $c s i-11, c s i-20$ and $c s i-101$ $\mathrm{MudJ}$ insertion sites, respectively, was obtained. BLAST searches of the sequence attained revealed that all three insertions were located at different sites within the $S$. typhimurium homologue of a hypothetical ORF from $E$. coli, designated $y a f H$ or orf188 (GenBank entries D38582 and D83536). Comparisons between the $S$. typhimurium and E. coli DNA and deduced amino acid sequences indicated that they are orthologous, showing $>95 \%$ (deduced) amino acid identity (Fig. 1). Sequence analysis indicated that the insertion in ST54 (csi-20) was proximal to the deduced translational start site (amino acid 178) followed by the insertion in ST64 (csi-101) and ST50 (csi-11), at deduced amino acids 324 and 546, respectively. Thus, unless otherwise indicated the fusion in ST54 was employed for the regulatory analysis performed in this study.

The E. coli yafH locus lies between $5 \cdot 1$ and $5 \cdot 2$ centisomes on the E. coli linkage map (Berlyn et al., 1996). However, the S. typhimurium homologue is predicted to map around 6.9 centisomes on the $S$. typhimurium genetic map, based upon the relative locations of known genes or markers in the region on the S. typhimurium and the E. coli linkage maps (Berlyn et al., 1996; Sanderson et al., 1996). However, linkage to known loci in this region has not been demonstrated (data not shown).

Fig. 1 indicates the location of each insertion relative to the E. coli yafH ORF sequence (GenBank entry D83536). The predicted ORF defining yaf $H$ potentially encodes a protein of 814 amino acids, YafH. BLASTP searches with the proposed YafH sequences from both E. coli and $S$. typhimurium demonstrated that $\mathrm{YafH}$ is homologous (20-50\% amino acid identity) to acyl-CoA dehydro- genase $(\mathrm{ACDH})$ enzymes from a range of bacterial and eukaryotic species and exhibits about $33 \%$ amino acid identity with the corresponding ACDH consensus sequence (see ProDom database release 34.2). This suggested that yafH of E. coli and our S. typhimurium homologue encodes an ACDH activity. The most prominent function of ACDH enzymes is in the $\beta$ oxidation of fatty acids (see Black \& DiRusso, 1994, for a review). Thus, one possibility was that the yafHencoded ACDH may represent the LCADH required for the utilization of medium- and long-chain fatty acids as $\mathrm{C}$-sources in these bacteria - in other words that yafH is identical to the proposed fadF gene (Klein, 1973; Overath et al., 1969; Klein et al., 1971; Black \& DiRusso, 1994).

\section{Phenotypic evidence that yafH is fadF}

To test the hypothesis that the $S$. typhimurium yafH homologue is $f a d F$, a number of phenotypic characterizations were carried out. Table 2 presents growth phenotypes of strains carrying each of the three insertions compared to their wild-type parent on NCE minimal agar plates with glucose, acetate or oleate $(\mathrm{a}$ long-chain monounsaturated fatty acid; $\mathrm{C}_{18: 1 \text { cis9 }}$ ) as the sole C-source. Strains carrying any of the three insertion mutations (ST50, ST54 or SMS645, and ST64) were all unable to utilize oleate as a sole C-source. In contrast, the wild-type parent strains (SL1344 and TR6583) were both capable of oleate utilization. Both the mutant and the parent strains grew well on NCE medium with acetate as the sole carbon and energy source, indicating they were all capable of metabolizing acetyl-CoA via the TCA cycle and glyoxylate shunt. This connotes that the defect in the mutants was in fatty acid degradation and not in the TCA cycle or steps following the TCA cycle. Thus, insertions disrupting the $y a f H \mathrm{ORF}$ up to deduced amino acid 546 (ST50_ORF, Fig. 1) all prevented utilization of oleate as a C-source, suggesting that all or part of the carboxy-terminal $33 \%$ of the deduced 814 amino acid protein is essential for its activity. These results also indicated that the encoded ACDH has a specificity for long-chain fatty acids (LCACDH). Be- 
Table 3. $\beta$-Oxidation activity and oleate induction of fadF expression in pertinent $S$. typhimurium strains

\begin{tabular}{|c|c|c|c|}
\hline Strain (pertinent genotype) & $\begin{array}{l}\text { Growth } \\
\text { medium }\end{array}$ & $\begin{array}{c}\beta \text {-Oxidation } \\
\text { specific activity } \\
{\left[\mathrm{nmol} \mathrm{min}^{-1}(\mathrm{mg}\right.} \\
\left.\text { protein })^{-1}\right] \dagger\end{array}$ & $\begin{array}{c}\beta \text {-Galactosidase } \\
\text { activity (Miller } \\
\text { units) } \neq\end{array}$ \\
\hline \multirow[t]{2}{*}{ SL1344 $\left(\mathrm{fadR}^{+} \mathrm{fadF^{+ }}\right)$} & TB & $0.15 \pm 0.06$ & ND \\
\hline & $\mathrm{TBO}$ & $1 \cdot 35 \pm 0 \cdot 16$ & ND \\
\hline \multirow[t]{2}{*}{ ST50 (fadR ${ }^{+}$fadF102::lac $)$} & TB & $<0.01$ & ND \\
\hline & $\mathrm{TBO}$ & $<0 \cdot 01$ & ND \\
\hline \multirow[t]{2}{*}{ ST54 (fadR fadF103::lac) } & $\mathrm{TB}$ & $<0 \cdot 01$ & $22 \cdot 5 \pm 10 \cdot 6$ \\
\hline & $\mathrm{TBO}$ & $<0.01$ & $326 \cdot 5 \pm 31 \cdot 80$ \\
\hline \multirow[t]{2}{*}{ TR6583 $\left(\mathrm{fadR}^{+} \mathrm{fadF}^{+}\right)$} & $\mathrm{TB}$ & $0.18 \pm 0.06$ & ND \\
\hline & $\mathrm{TBO}$ & $0 \cdot 784 \pm 0 \cdot 1$ & ND \\
\hline \multirow[t]{2}{*}{ LS1860 (fadR101 $\left.\mathrm{fadF}^{+}\right)$} & $\mathrm{TB}$ & $1 \cdot 30 \pm 0.08$ & ND \\
\hline & TBO & $0 \cdot 90 \pm 0 \cdot 08$ & ND \\
\hline
\end{tabular}

*Cells were grown in noninducing medium (tryptone broth; TB) or inducing medium (TB broth supplemented with $1 \mathrm{mM}$ oleate; TBO) to exponential phase. $\beta$-Oxidation or $\beta$-galactosidase activities (Miller, 1972, 1992) were then measured.

† Values are means \pm SEM from at least three separate trials. $\beta$-Oxidation specific activities of $<0.01$ are below the detection limit of the assay.

$\ddagger$ Values are means \pm SEM from at least three separate trials. ND, Not determined.

cause of these findings, we renamed this locus fadF based on nomenclature proposed by K. Klein and P. Overath (Klein, 1973; Overath et al., 1969; P. Overath, personal communication) as discussed below. The three insertions were also renamed to reflect this change: fadF102 (csi-11), fadF103 (csi-20) and fadF104 (csi101):: MudJ (lac $\left.\operatorname{Kan}^{\mathrm{R}}\right)$.

The results shown in Table 3 further support the redesignation of yafH as $\mathrm{fadF}$. These data indicated that not only was $f a d F C$-starvation inducible but it was also induced by the presence of oleate in nonlimiting TB medium. This was to be expected since oleate is known to induce enzyme activities involved in fatty acid degradation in E. coli (Black \& DiRusso, 1994). Data were only obtained for the deduced translational start site proximal fadF103: : lac fusion.

The hypothesis that the inability of these mutants to utilize oleate results from a defect in $\beta$-oxidation was supported by the data shown in Table 3 . These results showed that an insertion disrupting the ORF at either deduced amino acid 178 or 546 (Fig. 1) reduced $\beta$ oxidation specific activity to undetectable levels (ST54 and ST50, respectively). As expected, $\beta$-oxidation activity was oleate inducible in the parental strains (SL1344 and TR6583, TB vs TBO). Interestingly, the $\beta$-oxidation activity levels of the two wild-type strains following induction with oleate were different: activity measured in TR6583 was only about $58 \%$ of that measured in SL1344. This may be a reflection of the difference in the levels of induction of $f a d F$ observed in these two strain backgrounds (compare Tables 3 and 4, strains ST54 and
SMS645) since the FadF ACDH catalyses the ratelimiting step in $\beta$-oxidation in E. coli (Black \& DiRusso, 1994), and probably $S$. typhimurium as well. This explanation is supported by the fact that both the $\beta$ oxidation and $\beta$-galactosidase activity levels of the two wild-type strains during noninducing conditions (TB without oleate) are virtually identical.

\section{The fadF gene is a phase 1 SSR locus}

Expression of the fadF103::lac fusion was followed over time during growth in minimal limiting glucose broth. The results showed that $f a d F$ is a phase $1 \mathrm{C}$ starvation-inducible locus, i.e. it is induced during the transition from growth to C-starvation-induced stationary phase (Fig. 2). The fadF103::lac fusion exhibited increased $\beta$-galactosidase expression upon the cessation of growth due to exhaustion of glucose in the medium (Fig. 2 insert) (Spector et al., 1988; Spector \& Cubitt, 1992; Spector \& Foster, 1993). In addition, fadF expression continued at a high rate over the next $160 \mathrm{~h}$ of C-starvation. Results are shown for the fadF103: : lac fusion but similar results were obtained for the fadF102: : lac and fadF104: : lac fusions.

The fadF103: : lac fusion was also consistently induced during P-starvation, but only about sixfold; however, the fadF103: : lac fusion was not $\mathrm{N}$-starvation responsive. Although the P-starvation-induction of $\mathrm{fadF}$ exhibited similar kinetics to that observed during Cstarvation, P-starvation-induction of $f a d F$ was not nearly to the level observed for C-starvation (data not shown). 


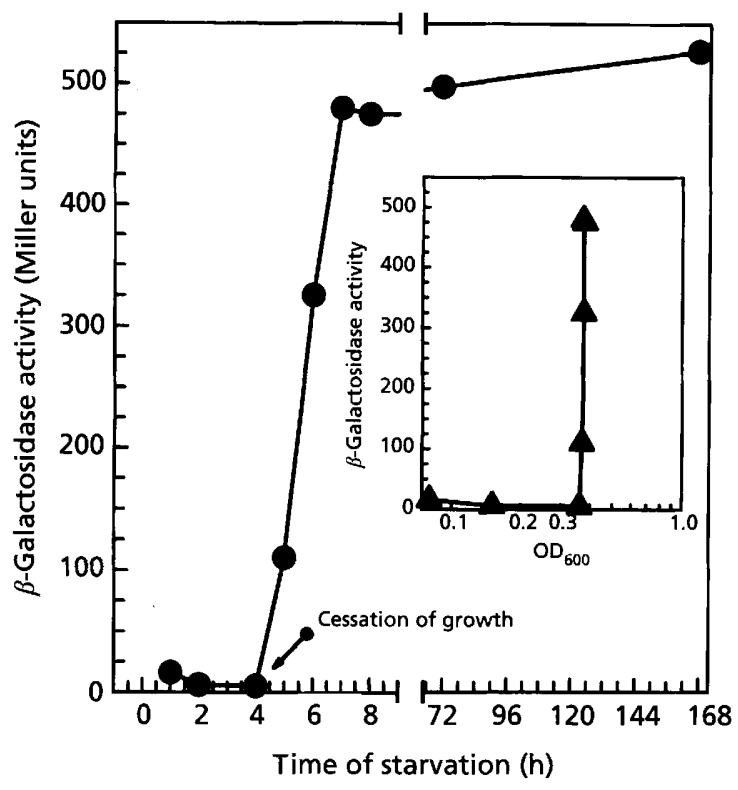

Fig. 2. Induction kinetics of fadF expression. ST54 [fadF103 (csi-20)::lac] was diluted 1:100 from an overnight MS hiPCN culture into fresh MS loC medium and grown at $37^{\circ} \mathrm{C}$ with shaking. At the indicated time intervals aliquots were removed and $\beta$-galactosidase activity was measured (Miller, 1972, 1992). The arrow indicates the point at which the culture stopped growing due to exhaustion of glucose from the medium. The insert shows the same data with $\beta$-galactosidase activity plotted versus growth as measured by $\mathrm{OD}_{600}$. The data presented are representative of results from at least three separate trials.

\section{FadR is a negative regulator of fadF expression during exponential-phase growth}

The fadR gene product is a global regulator of several fatty acid biosynthesis $(f a b)$ and fatty acid degradation $(\mathrm{fad})$ genes. Evidence to date suggests that it is a positive transcriptional regulator for two $f a b$ genes and a negative regulator of at least seven fad genes in E. coli (DiRusso et al., 1992, 1993; Gui et al., 1996: Farewell et al., 1996; reviewed by Black \& DiRusso, 1994; DiRusso \& Nyström, 1998). In addition, it also negatively regulates the uspA locus, which encodes a universal stress protein (Farewell et al., 1996). Growth of E. coli cells in media containing long-chain fatty acids results in derepression of $f a d B A, f a d D, f a d L$ and $u s p A$ genes as well as the diminution of $f a b A$ gene expression (Farewell et al., 1996; reviewed by Black \& DiRusso, 1994; DiRusso, 1996; DiRusso \& Nyström, 1998). However, a role of FadR in the regulation of $\mathrm{fab}$ or $\mathrm{fad}$ gene expression during C-starvation (in the absence of exogenously added long-chain fatty acids) has not been directly established. To test if FadR is a regulator of fadF expression during C-starvation in S. typhimurium, we first needed to isolate a fadR mutant of $S$. typhimurium. This was accomplished by screening for colonies that grew on NCE minimal agar medium containing decanoate as a sole C-source. Growth on decanoate is a defining phenotype of strains carrying a mutation in $f a d R$. The reason for this is that the acyl-
CoA derivative of this medium-chain fatty acid does not bind to FadR (cannot act as an inducer) and, thus, cannot cause the derepression of $\mathrm{fad}$ gene expression (DiRusso et al., 1992; Raman \& DiRusso, 1995). Using this screening procedure a $f a d R$ mutant (LS1860) was isolated and confirmed by $\beta$-oxidation activity assays. Table 2 illustrates that LS1860 could grow on both medium-chain (decanoate) and long-chain (oleate) fatty acids as a sole $\mathrm{C}$-source, as expected. Table 3 indicates that LS1860 exhibited derepressed levels of $\beta$-oxidation activity in the absence of long-chain fatty acids. These findings support the conclusion that LS1860 is a $\mathrm{fadR}$ mutant, lacking a functional FadR repressor activity. Furthermore, the finding that introduction of pCD101 (which encodes a wild-type E. coli FadR protein) into LS1860 restored inducibility of $\beta$-oxidation activity in response to oleate (data not shown) confirmed that the mutation was in $f a d R$, and it was designated $f a d R 101$.

We also tested whether a fadR101 fadF103: : lac double mutant (SMS648) could grow on decanoate as a sole Csource. As seen in Table 2, LS1860 grew on NCE decanoate but SMS648 could not grow on decanoate. This indicated that the $\mathrm{fadF}$-encoded ACDH was also required for the utilization of medium-chain fatty acids, further supporting the hypothesis that $f a d F$ encodes an LCACDH activity.

The fadR101 mutation was isolated in the TR6583 background, so the fadF103:: lac insertion was transduced into both TR6583 and LS1860, and fadF103::lac expression was monitored during exponential-phase growth with or without exogenously added oleate and during C-starvation. Results presented in Table 4 indicated that, as hypothesized, FadR is a repressor of fadF transcription under non-inducing conditions (exponential-phase growth in the absence of oleate; compare SMS645 and SMS648, exponential-phase/ minimal and exponential-phase/TB). The fadR101 mutation resulted in derepression of the fadF103: : lac fusion to levels observed during C-starvation. This derepression occurred in the absence of appreciable cAMP:CRP (high glucose levels in the medium) or ppGpp (growing cells) levels (see below). Interestingly, fadF103::lac still exhibited about a $2 \cdot 5$-fold induction during C-starvation in a fadR101 background. This additional level of induction was found to require cAMP: CRP (data not shown). Thus, in the absence of a functional FadR repressor, cAMP:CRP (accumulating as a result of glucose-starvation) can lead to two- to threefold higher levels of fadF induction during Cstarvation. These results and others (Fig. 2) also demonstrated that the C-starvation-induction of $\mathrm{fadF}$ occurs in the absence of exogenously added inducer, i.e. exogenously added long-chain fatty acid derived acylCoAs.

One other interesting finding was observed when we compared the level of induction of the fadF103::lac fusion and $\beta$-oxidation activities in the SL1344 and TR6583 backgrounds. As mentioned above, $\beta$-oxidation activity in the TR6583 strain was only about $58 \%$ of 
Table 4. Effect of the fadR101 mutation on fadF expression during C-starvation and growth in the presence of oleate

\begin{tabular}{|llr|}
\hline Strain (pertinent genotype) & \multicolumn{1}{c|}{ Growth condition* } & $\begin{array}{c}\boldsymbol{\beta} \text {-Galactosidase activity } \\
\text { (Miller units) } \dagger\end{array}$ \\
\hline SMS645 (fadR ${ }^{+}$fadF103::lac) & Exponential phase/minimal & $11 \cdot 17 \pm 0 \cdot 46$ \\
& 3 h C-starved & $212 \cdot 09 \pm 0 \cdot 73$ \\
& Exponential phase/TB & $24 \cdot 61 \pm 3 \cdot 45$ \\
& Exponential phase/TB + oleate & $185 \cdot 90 \pm 9 \cdot 33$ \\
SMS648 (fadR101 fadF103::lac) & Exponential-phase/minimal & $271 \cdot 04 \pm 19 \cdot 14$ \\
& 3 h C-starved & $700 \cdot 39 \pm 59 \cdot 04$ \\
& Exponential phase/TB & $313 \cdot 48 \pm 1 \cdot 10$ \\
& Exponential phase/TB +oleate & $228.83 \pm 6.94$ \\
\hline
\end{tabular}

* Cells were grown under noninducing conditions [exponential phase in nonlimiting minimal or tryptone broth (TB) media] or under inducing conditions $[3 \mathrm{~h}$ of $\mathrm{C}$-starvation in minimal medium or exponential phase in TB $+1 \mathrm{mM}$ oleate broth medium). $\beta$-Galactosidase activity was then measured according to the method of Miller $(1972,1992)$.

†Values are means \pm SEM from at least three separate trials.

Table 5. Roles of the rpoS, cya/crp, relA/spot and fadR loci in fadF expression during C-starvation

\begin{tabular}{|c|c|c|c|}
\hline \multirow[t]{2}{*}{ Strain (pertinent genotype) } & \multicolumn{2}{|c|}{$\beta$-Galactosidase activity ${ }^{*}$} & \multirow{2}{*}{$\begin{array}{l}\text { Mean fold- } \\
\text { induction } t\end{array}$} \\
\hline & Exponential phase & 3 h C-starved & \\
\hline ST54 (fadF103::lac) & $4 \cdot 41 \pm 1 \cdot 15$ & $450 \cdot 50 \pm 13 \cdot 20$ & 102 \\
\hline SMS452 (fadF103:: lac rpoS::3-Amp) & $2 \cdot 51 \pm 0 \cdot 50$ & $399 \cdot 02 \pm 27 \cdot 49$ & 160 \\
\hline SMS506 (fadF103:: lac cya:: Tn10) & $4 \cdot 41 \pm 1 \cdot 10$ & $4 \cdot 38 \pm 2 \cdot 01$ & $1 \cdot 0$ \\
\hline SMS451 (fadF103: : lac crp-773:: Tn10) & $3 \cdot 27 \pm 1 \cdot 33$ & $2 \cdot 62 \pm 3 \cdot 70$ & $0 \cdot 8$ \\
\hline SMS572 (fadF103:: lac cya::Tn10 crp*-771) & $6 \cdot 17 \pm 2 \cdot 20$ & $160 \cdot 50 \pm 4 \cdot 51$ & 26 \\
\hline SMS505 (fadF103: : lac relA21:: Tn10) & $2 \cdot 47 \pm 0 \cdot 42$ & $176 \cdot 21 \pm 14 \cdot 83$ & 71 \\
\hline SMS566 (fadF103: : lac spoT1) & $6 \cdot 42 \pm 1 \cdot 56$ & $256.66 \pm 13.89$ & 40 \\
\hline SMS567 (fadF103: : lac spoT22) & $3 \cdot 92 \pm 1 \cdot 38$ & $191 \cdot 94 \pm 13 \cdot 81$ & 49 \\
\hline SMS568 (fadF103:: lac spo $\left.T^{+}\right)$ & $4 \cdot 73 \pm 2 \cdot 37$ & $463 \cdot 81 \pm 10 \cdot 47$ & 98 \\
\hline SMS569 (fadF103: : lac relA spoT1) & $5 \cdot 27 \pm 0.93$ & $195 \cdot 34 \pm 15 \cdot 29$ & 37 \\
\hline SMS570 (fadF103:: lac relA spoT22) & $3 \cdot 35 \pm 1 \cdot 13$ & $238 \cdot 36 \pm 5 \cdot 37$ & 71 \\
\hline SMS571 (fadF103: : lac relA spo $\left.T^{+}\right)$ & $3.82 \pm 1.05$ & $171 \cdot 77 \pm 24 \cdot 33$ & 45 \\
\hline
\end{tabular}

*Each strain was grown under noninducing conditions (exponential-phase in nonlimiting minimal medium) or inducing conditions ( $3 \mathrm{~h}$ of $\mathrm{C}$-starvation in minimal medium), at which point $\beta$ galactosidase activity was measured by the method of Miller $(1972 ; 1992)$. Values are means \pm SEM from at least 3 separate trials.

$†$ Mean fold-induction is calculated by dividing the mean $\beta$-galactosidase activity under inducing conditions by the mean $\beta$-galactosidase activity under noninducing conditions.

that measured in SL1344 (Table 3). This correlates well with the finding that fadF103:: lac was induced in the TR6583 background to only about $57 \%$ of that observed in the SL1344 background during growth in TBO (compare SMS645, TBO, in Table 4 to ST54, TBO, in Table 3). Similarly, the level of induction of this fusion, during C-starvation, in the TR6583 background was only about $47 \%$ that observed in the SL1344 background (compare SMS645, 3 h C-starved, in Table 4 with ST54, $3 \mathrm{~h}$ C-starved, in Table 5). The reason for this disparity is not clear at this time.

\section{Induction of fadF during C-starvation is $\sigma^{\text {s-independent }}$}

Several C-starvation-inducible SSR loci are under the control of the alternative sigma transcription factor encoded by the $r p o S$ gene, $\sigma^{\mathrm{S}}$ or $\sigma^{38}$ (O'Neal et al., 1994; reviewed by Hengge-Aronis, 1996; Spector, 1998). Therefore, we wanted to test if $\mathrm{fad} F$ is under $\sigma^{\mathrm{s}}$ control. An $r p o S: \mathrm{Amp}^{\mathrm{R}}$ (Fang et al., 1992; O'Neal et al., 1994) null insertion mutation was introduced into the fadF103::lac fusion-carrying strain. The resulting 
strain, SMS452, was then assayed for induction during C-starvation. As shown in Table 5, fadF103:: lac induction levels, although slightly lower, were not significantly different in the rpoS background compared to the $r p o S^{+}$background (compare SMS452 with ST54). Similar results were seen for the other two fadF: lac fusions (data not shown). Thus, the induction of $\mathrm{fad} F$ appears to be $\sigma^{\mathrm{s}}$-independent.

\section{Induction of fadF during C-starvation is CAMP: CRP-dependent}

Another global regulator of C-starvation-inducible gene expression is the cAMP:CRP complex (Spector \& Cubitt, 1992; reviewed by Saier et al., 1996; Spector, 1998). This regulator has also been implicated in the regulation of other fatty acid metabolism genes (Black \& DiRusso, 1994; DiRusso \& Nyström, 1998). Therefore, we introduced a crp-773:: Tn10 (lacks the cAMP receptor protein, CRP) or a $c y a:: \operatorname{Tn} 10$ (lacks adenylate cyclase activity) null insertion mutation into the fadF103:: lac-carrying strain, and the resulting strains, SMS451 and SMS506, were then assayed for induction during C-starvation. No significant induction of the fadF103: : lac fusion during C-starvation was detected in either the $c y a$ or $\operatorname{cr} p$ mutant (Table 5). Similar results were obtained for the other fadF: : lac fusions (data not shown). Thus, cAMP:CRP is a positive regulator required for the C-starvation-induction of $\mathrm{FadF}$.

As mentioned above cAMP: CRP is also required for the increased level of $\mathrm{fadF}$ expression observed in a fadR101 mutant during C-starvation (data not shown). This might suggest that the primary function of cAMP: CRP is to enhance RNA polymerase transcription of $\mathrm{fadF}$, in addition to, or rather than, relieving FadR repression. To address this question we introduced a $c r p^{*}-771$ mutation into a cya::Tn10 fadF103::lac strain. The resulting strain, SMS572, produces red colonies on MacConkey's $0.5 \%$ mannitol agar plates whereas its cya:: Tn10 parent, SMS506, is white/yellow on this medium (data not shown). SMS572 was assayed for $f a d F$ expression under noninducing and inducing conditions. As illustrated in Table 5, the $c r p^{*}$ mutation restored C-starvation-inducibility to fadF103: : lac, albeit not to wild-type levels, but did not result in derepression of $\mathrm{fadF}$ expression under noninducing conditions in exponential-phase cells. This indicates that cAMP:CRP alone is not sufficient to relieve FadR repression and that FadR must be inactivated in order to achieve fadF induction under the conditions tested.

\section{Induction of fadF during C-starvation is partially dependent upon the accumulation of (p)ppGpp}

The accumulation of (p)ppGpp as a result of C-starvation is also known to control, at least in part, Cstarvation-inducible gene expression (Spector \& Cubitt, 1992; reviewed by Cashel et al., 1996, Spector, 1998). There are two (p)ppGpp synthetase activities in both $E$. coli and Salmonella: one is encoded by relA (ppGpp synthetase I) and the other is encoded by spoT (ppGpp synthetase II, which is also a ppGpp 3'-pyrophosphohydrolase involved in ppGpp degradation). The accumulation of ppGpp elicits what is referred to as the stringent response, best characterized during amino acid starvation (reviewed by Cashel et al., 1996). There have been conflicting results concerning the accumulation of ppGpp during C-starvation with regard to which enzyme is involved in its synthesis and/or whether reduced degradation by SpoT accounts for ppGpp accumulation under these conditions. Some studies suggest that ppGpp accumulation during C-starvation is SpoT-dependent and RelA-independent; others found that this is not the case (reviewed by Cashel et al., 1996). We have previously shown, however, that the Cstarvation-induction of several SSR loci is relA-dependent (Spector \& Cubitt, 1992; M. Spector, unpublished results). Therefore we wanted to determine if the expression of $f a d F$ is dependent on ppGpp during $\mathrm{C}$-starvation. To examine this possibility, the Cstarvation-inducibility of fadF103:: lac was measured in relA, spoT and relA spoT double-knockout mutation backgrounds. As presented in Table 5, the results of these experiments indicated that ppGpp, although not absolutely required for $\mathrm{C}$-starvation-induction as in the case of cAMP:CRP, is required for the full induction of fadF during C-starvation. What is less clear from these results is which ppGpp synthetase is (most) important for ppGpp synthesis under these conditions. Results presented in Table 5 show that strains which lack RelA but possess SpoT (SMS505 and SMS571) exhibited only about $40 \%$ the level of induction of $\mathrm{fadF}$, as compared to wild-type strains, during C-starvation. Interestingly, strains carrying one of two null spoT mutations (Rudd et al., 1985; SMS566 and SMS567), which would lack a functional SpoT enzyme but possess RelA, also exhibited reduced levels of fadF induction $(40-55 \%$ of the wild-type levels) during C-starvation. This suggests that both ppGpp synthetases play a role in ppGpp synthesis under these conditions. Based on these findings, one might expect that a relA spoT double, or ppGpp $^{0}$ (Rudd et al., 1985), null mutant would not exhibit C-starvation-induction of $f a d F$. However, data presented in Table 5 indicated that this was not the case, since the double relA spoT mutants exhibited levels of $\mathrm{fadF}$ induction equivalent to strains carrying the relA or spoT mutations alone. Strains SMS568 and SMS571 were included as controls to demonstrate that the $\operatorname{Tn} 10$, used for transduction of the $s p o T$ mutations, itself was not having an effect on fadF103: : lac expression. These data connote that ppGpp is needed in some manner (i.e. directly or indirectly; at the transcriptional or posttranscriptional level) for full induction of $\mathrm{fadF}$ and that both the RelA and SpoT enzymes appear to play a role in ppGpp synthesis under these conditions.

Although the mean fold-inductions of fadF103: : lac vary between 37 and 71 for strains carrying relA and/or spoT mutations this is primarily a reflection of the slight differences in the basal levels of expression measured in these strain backgrounds as opposed to differences in the induced levels of expression of $\mathrm{fadF}$. The basal ex- 


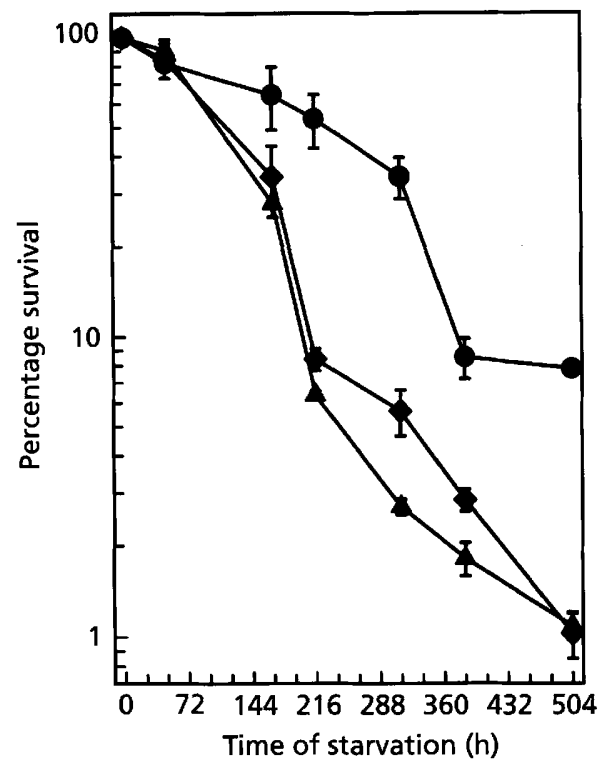

Fig. 3. C-starvation-survival of fadf mutant strains. SL1344 (wild-type parent, O), and its fadF102::lac (ST50, $\boldsymbol{\Delta}$ ) and fadF103:: lac (ST54, $\downarrow)$ mutant derivative strains were C-starved for a total of $504 \mathrm{~h}$. At the indicated time intervals aliquots were removed and viability measured. Maximum viability $\left(100 \%\right.$ survival) was typically about $3-5 \times 10^{8}$ c.f.u. $\mathrm{ml}^{-1}$. The values presented are means \pm SEM for at least three separate trials.

pression levels (i.e. expression during noninducing conditions) were not significantly different in these mutant backgrounds compared to the wild-type background. However, the induced levels of $f a d F$ in the wildtype and various mutant strain backgrounds was significantly different. Thus, the effect of the relA and/or the spoT mutations was on the level of C-starvationinduction only and not on basal fadF expression.

\section{fadF is needed for C-starvation-survival}

We had previously identified three C-starvationinducible SSR loci that are required for long-term starvation-survival, stiA, stiB and stiC (Spector \& Cubitt, 1992; O’Neal et al., 1994). Thus, we are interested in determining if other $\mathrm{C}$-starvation-inducible SSR loci are also needed for starvation-survival in $S$. typhimurium. To test this, we C-starved strains ST50 and ST54 for up to $504 \mathrm{~h}$ and measured culture viability at designated time intervals. The ST64 strain was not tested because the insertion in this strain lies between the insertions in ST54 (promoter proximal) and ST50 (promoter distal). Fig. 3 shows the results of these experiments. As can be seen in this figure, the MudJ insertion mutations in both ST50 and ST54 resulted in a more rapid loss of viability and about a 12 -fold lower level of survival compared to the parent strain SL1344 after $312 \mathrm{~h}$ of $\mathrm{C}$-starvation and about a sevenfold lower percentage survival after $504 \mathrm{~h}$. Furthermore, loss of viability in the fadF mutants had not reached a steadystate level by $21 \mathrm{~d}$, in contrast to the wild-type parent strain, which reached steady state after about $384 \mathrm{~h}$ of
C-starvation (Fig. 3). This suggests that FadF and fatty acid degradation, in general, are needed for survival of C-starved cells during the first two weeks or so of starvation and may also be important in maintaining steady-state viability after about three weeks of Cstarvation.

Since MudJ insertions are often polar in their effects on downstream genes in an operon, it is possible that a downstrëam gene rather than $f a d F$ is what is required for long-term survival of C-starved cells. Examination of the DNA sequence in E. coli both immediately upstream and downstream of the proposed $y a f H / f a d F$ ORF argues against $f a d F$ being part of an operon. The two ORFs present, based on sequence analysis, would both be transcribed in the opposite direction to $f a d F$. It is likely that the same is true for this region in $S$. typhimurium, given the conservation of known sequence between the E. coli and Salmonella yafH/fadF and the organization of genetic loci in this region. Thus, it is unlikely that the phenotypes described were the result of polar effects on downstream genes - although we have not ruled out this scenario conclusively.

\section{The fadF gene is induced within cultured MDCK epithelial cells but is not required for lethality in mice}

Since $S$. typhimurium is an intracellular pathogen it is useful to know whether or not a gene is expressed in the host environment. This knowledge may provide insight into the conditions present in an intracellular environment as well as clues as to the potential importance of a locus in pathogenesis (Mahan et al., 1995; Valdivia \& Falkow, 1997). To this end, strains ST 54 and ST64 were incubated in the presence of MDCK epithelial cells in tissue culture, and allowed to be internalized within these cells. At $6 \mathrm{~h}$ post-infection, intracellular bacteria were harvested, and $\beta$-galactosidase activity was assayed and compared with the activity in extracellular bacteria. Results from these experiments indicate that $\mathrm{fadF}$ was induced $11 \cdot 6 \pm 4 \cdot 5$-fold (mean \pm SEM, $n=5$ ) within MDCK epithelial cells (data not shown). This is comparable to the approximately 14.5 -fold induction seen during growth in TB medium containing oleate (Table 3).

Because $f a d F$ was induced intracellularly, we wanted to test if this locus is also important for pathogenesis in the mouse virulence model for S. typhimurium. To examine this, the virulent strain SL1344 and its fadF derivatives (ST50, ST54 and ST64) were each given by oral gavage to five BALB/c mice. In an initial screening test, a dose of $10^{8}$ cells of each strain (roughly 1000-fold more than the expected oral $\mathrm{LD}_{50}$ ) was administered. All mice given either the mutant or wild-type strains died within $14 \mathrm{~d}$, except two mice given ST54. To confirm these findings, SL1344 and ST54 were inoculated orally at different doses into separate groups of mice to determine the relative $\mathrm{LD}_{50}$ values. Mice were monitored for $28 \mathrm{~d}$. The $\mathrm{LD}_{50}$ values were calculated to be approximately $10^{4 \cdot 5}$ for SL1344 and $10^{5 \cdot 1}$ for ST54 (only about fourfold 
higher). Thus, the fadF mutant was not notably attenuated in terms of lethality in the mouse, compared to the wild-type parent strain.

\section{DISCUSSION}

In this study we have identified and characterized three independently isolated $\mathrm{Mud}$-directed lac transcriptional fusions from a library of S. typhimurium strains carrying $\mathrm{C}$-starvation-inducible lac fusions. Sequence analysis of chromosomal DNA adjacent to the insertion sites showed that all three lie within the same gene, which exhibits $>95 \%$ amino acid sequence identity with the E. coli ORF designated YafH or orf188 (GenBank accession numbers D38582 and D83536). Disruption of the gene at each of the three Mud-lac insertion sites eliminated both growth on medium- and long-chain fatty acids, as the sole carbon and energy source, and in vivo $\beta$-oxidation. By comparison with wellcharacterized enzymes and based on the phenotypic characterization of strains ST50, ST54 and ST64 reported here, we propose that this ORF encodes an acyl-CoA dehydrogenase (ACDH) with chain length specificity for medium- and long-chain fatty acids (LCACDH); therefore, we have designated this gene fadF to reflect established nomenclature (Klein, 1973; Overath et al., 1969; reviewed by Black \& DiRusso, 1994; DiRusso \& Nyström, 1998).

Despite the proposal of Klein (1973) that, in addition to the $f a d F$-encoded LCACDH, a short-chain fatty acid $\mathrm{ACDH}(\mathrm{FadG})$ is also encoded in the $5 \mathrm{~min}$ region of $E$. coli, only the ORF designated $y a f H$ can be identified as an ACDH by comparison to well characterized enzymes (Fig. 1). The YafH (FadF) ORF potentially encodes a polypeptide of 814 amino acids. Most ACDH enzymes characterized to date are only $400-600$ amino acids in length. Thus, the E. coli and Salmonella enzymes appear to be much longer than their eukaryotic counterparts, with only about 450 amino acids in the amino-terminal portion of FadF sharing $30 \%$ or more identities with the eukaryotic enzymes. Interestingly, the MudJ-lac insertion in ST50 was inserted after amino acid 546 of the ORF; yet the same phenotypes associated with insertions located more amino-terminally (ST54 and ST64) are also ascribed to the insertion in ST50. We postulate, therefore, that this indicates that portions of the protein in the carboxy-terminal region which do not share significant identities with the larger family of $\mathrm{ACDH}$ enzymes are required for enzyme function in these bacteria. This may indicate significant differences between the enzymes, which will require further study. What the function of this carboxy-terminal region might be is unclear since it does not show significant homology to any known sequences within the GenBank or other databases.

Evidence from studies examining the regulation of other E. coli fad genes or enzyme activities has previously implicated cAMP: CRP as a positive regulator and FadR as a negative regulator (DiRusso et al., 1992; Farewell et al., 1996; reviewed by Black \& DiRusso, 1994). Fatty acid biosynthesis is also under positive stringent control; fatty acid degradation has not been tested (reviewed by Black \& DiRusso, 1994; DiRusso \& Nyström, 1998). Results presented here show that the S. typhimurium fadF gene is regulated by FadR, cAMP : CRP and ppGpp (Tables 3, 4 and 5).

As previously described for other fad genes in E. coli (DiRusso et al., 1992; Farewell et al., 1996), FadR functions as a negative regulator of $f a d F$, repressing $f a d F$ expression in exponential-phase cells in the absence of exogenous long-chain fatty acids (inducer). In contrast, cAMP:CRP is required for the positive regulation of fadF expression during C-starvation. The cAMP: CRP complex is absolutely required for the C-starvationinduction of $\mathrm{fadF}$ since mutations preventing the synthesis of cAMP (i.e. cya::Tn10 insertion mutation) or the cAMP receptor protein (i.e. crp:: $\operatorname{Tn} 10$ insertion mutation) both eliminated the C-starvation-induction of fadF (Table 5). In further support of these findings, a DNA fragment containing a putative promoter upstream of the E. coli yafH ( $\mathrm{fadF}$ ) (GenBank entry D83536) was fused to the $l a c Z$ gene and $\beta$-galactosidase activity assayed. The promoter of the $E$. coli gene, like the $S$. typhimurium gene, was also found to be regulated by FadR and glucose-mediated catabolite repression. The FadR-binding site ( 5 ' AAGTGGTCAGACCTTCCT $3^{\prime}$ ) identified by DNase I footprinting with purified FadR is found 21 bp upstream of the start of translation and is within the predicted promoter region for the E. coli yafH $(f a d F)$ gene (C. C. DiRusso, unpublished results). The data showing that $\mathrm{fadF}$ expression is not derepressed during noninducing conditions in a cya $\mathrm{crp}$ * double mutant suggest that the role of CAMP:CRP is primarily to activate $\mathrm{fadF}$ transcription in the absence of FadR repression (Tables 4 and 5 ; data not shown). This implies that the FadR repressor must be inactivated during C-starvation in order for cAMP: CRP to activate $\mathrm{fadF}$ transcription. The inactivation of FadR repression may involve (a) the release of endogenous inducers (e.g. long-chain fatty acyl-CoAs derived from inner-membrane fatty acid residues) or (b) some other signal generated during the C-SSR. Whether C-starvationinduction of $\mathrm{fadF}$ is independent of long-chain fatty acyl-CoAs remains to be determined. However, it can be postulated that their long-chain fatty acid precursors may become available as a result of: (a) membrane turnover (endogenous inducer), as cells enter and proceed into C-starvation-elicited stationary phase, and/or (b) being released as dying cells lyse in the vicinity (exogenous inducer). Irrespective of the control of $f a d F$ induction, at least three findings indicate that the ability to utilize medium-/long-chain fatty acids is a key event in the SSR. First, the cellular levels of monounsaturated fatty acids, such as cis-vaccenic acid, decrease significantly during starvation (reviewed by Huisman et al., 1996; DiRusso \& Nyström, 1998). Secondly, $f a d F$ is continually expressed at a high level over the first week of C-starvation (Fig. 2) and, thirdly, fadF mutants exhibit reduced C-starvation-survival (Fig. 3). 
MudJ insertions disrupting the fadF ORF at deduced amino acids 178 or 546 significantly reduced the Cstarvation-survival of strains carrying these insertions (Fig. 3). These mutants consistently lose viability more rapidly and they survive at about a sevenfold lower level and fail to establish a steady-state survival level, compared to wild-type strains, after $21 \mathrm{~d}$ starvation. This effect on starvation-survival is interesting because previous findings in E. coli (Schultz et al., 1988) have suggested that only cAMP: CRP-independent genes (i.e. not requiring CAMP for their induction) are critical to starvation-survival. Furthermore, evidence from both $E$. coli and $S$. typhimurium (reviewed by Hengge-Aronis, 1996; Spector, 1998) has suggested that $\sigma^{\mathrm{S}}$-dependent loci are key to starvation/stationary-phase survival; but, results presented here show that fadF expression is $\sigma^{\mathrm{S}}$ independent (Table 5). However, the role of $\mathrm{fadF}$ as a $\mathrm{C}$-starvation-survival locus is consistent with the finding that it is a phase 1 SSR locus, since the core SSR loci identified to date are also phase 1 loci that exhibit continued expression over the first several days of starvation (Spector et al., 1988; Spector \& Cubitt, 1992; reviewed by Spector, 1998). Although two of these starvation-survival loci are $\sigma^{\mathrm{s}}$-dependent and another is negatively controlled by $\sigma^{\mathrm{S}}$, none require cAMP:CRP for their induction (Spector \& Cubitt, 1992; O'Neal et al., 1994). Thus, to our knowledge, this is the first report of a cAMP: CRP-dependent $\sigma^{\mathrm{S}}$-independent locus that plays a role in long-term starvation-survival, although other $\sigma^{\mathrm{S}}$-independent loci have been implicated in stasissurvival (Farewell et al., 1996; DiRusso \& Nyström, 1998). The reason why fadF mutants survive C-starvation poorly is not clear, but possible explanations include: (a) the inability to turn over fatty acids derived from the membrane during the initial phases of SSR, (b) the inability to utilize exogenous long-chain fatty acids that may become available as cells die and lyse during starvation, and/or (c) the accumulation of fatty acid molecules intracellularly or extracellularly as a result of their inability to be degraded.

A recent report has looked at the expression of E. coli $f a d B, f a d L, f a d D$ and $u s p A$ (which encodes the universal stress response protein, UspA) during stationary phase. The expression of the fad genes and uspA is increased upon entry into stationary phase in the absence of exogenously added fatty acids (Farewell $e t$ al., 1996). In contrast, the expression of $f a b A$ (fatty acid biosynthesis) is decreased during stationary phase. The growth-phasedependent increased and decreased transcription of $u s p A$, these $f a d$ genes and $f a b A$, respectively, are dependent upon inactivation or decreased expression of FadR (Farewell et al., 1996). Cells carrying the FadR super-repressor allele, fadRS219N, survive long-term stasis poorly following growth in rich medium, suggesting that the inability to derepress the FadR regulon is detrimental to the cell in stasis (Farewell et al., 1996). The present study supports the idea that FadR and the fad genes are important to non-growing cells by showing that fatty acid degradation is required for survival under the more defined conditions of carbon starvation. Clearly, the FadR protein and the genes it regulates play an important role in adaptation to and survival during stress.

Further support for a role for $f a d F$ in achieving maximal $\mathrm{C}$-starvation-survival comes from the finding that the alarmone (p)ppGpp appears to play a positive role in fadF induction during C-starvation. This alarmone has classically been associated with the stringent response first described for amino acid starvation but also found to accumulate during $\mathrm{C}$-/energy, $\mathrm{P}$ - and $\mathrm{N}$-starvation conditions (reviewed by Cashel et al., 1996). The enzymes involved in the synthesis and accumulation of (p)ppGpp are encoded by the relA and spoT genes. The SpoT enzyme is thought to be involved in (p)ppGpp accumulation during C-starvation but we have previously found that RelA is also involved in C-starvationelicited ( $\mathrm{p}$ )ppGpp accumulation (Spector \& Cubitt, 1992; reviewed by Cashel $e t$ al., 1996). Results presented here (Table 5) indicate that both the relA- and spoTencoded enzymes are needed for (p)ppGpp accumulation and positive control of $\mathrm{fadF}$ expression during Cstarvation. Mutations knocking out either enzyme reduced $\mathrm{fadF}$ induction $40-60 \%$ compared to wild-type levels, suggesting that ppGpp is required, directly or indirectly, for the full induction of $f a d F$ under the conditions tested. However, ppGpp accumulation alone is not sufficient to achieve fadF induction during Cstarvation in the absence of cAMP: CRP (Table 5). Our results also indicate that both RelA and SpoT are needed to achieve sufficient levels of (p)ppGpp to enhance $\mathrm{fadF}$ expression, since knocking out both enzyme activities (as in the relA spoT double mutant; Table 5) has the same effect as eliminating RelA or SpoT alone. It could be argued that the effects associated with the $\operatorname{rel} A$ and spoT mutations may be due to a general defect in gene expression or the consequence of the reporter system that we are using to monitor regulation, i.e. MudJ-lac transcriptional fusions. If this is the case then one would expect that all such fusions induced under similar Cstarvation conditions would exhibit relA and/or spoT control; however, they do not (see reviews by DiRusso \& Nyström, 1998; Spector, 1998), which tends to argue against such a nonspecific effect.

We also report here that $f a d F$ is significantly induced within cultured MDCK epithelial cells, and that this induction is comparable to induction by oleate. This suggests that the intravacuolar microenvironment in which S. typhimurium is located (a) has free fatty acids available to be taken up and utilized by the bacteria and/or (b) the intravacuolar milieu is limiting in available C-sources, especially glucose. Results from other studies indicate that the intravacuolar niche is limiting in glucose, but does contain mannose (F. Garcia del Portillo \& B. B. Finlay, unpublished results), a utilizable sugar for Salmonella. A previous report, supporting our findings, has suggested that fad genes are specifically expressed during Salmonella pathogenesis (Mahan et al., 1995). It is clear, however, from these various studies that stationary phase, $\mathrm{C}$-starvation and 
pathogenesis are each situations that demand significant, perhaps overlapping, alterations in cellular metabolism to favour survival during severe stress.

Although the intravacuolar expression of $\mathrm{fadF}$ did not correlate with an overt role in mouse virulence, it still provides important insight into the host-pathogen relationship. Life within the host organism(s) is an integral part of the life cycle of the various $S$. enterica serovars (Finlay \& Falkow, 1989). In fact, many serovars have adapted to life within a specific host, e.g. S. typhi is thought to exclusively infect humans. We tend to focus on factors that directly or overtly influence virulence, as measured in the mouse virulence model for $S$. typhimurium, but understanding how a pathogen obtains nutrients and resists environmental stresses in order to grow within a host is also essential to fully understanding the host-pathogen relationship even if individual factors important to these processes do not overtly affect virulence.

\section{ACKNOWLEDGEMENTS}

The authors would like to thank Ray Delio, Wayne Gabriel, Ken Snell and Rebel Hill for technical assistance, Marc Woodland for automated sequencing help, and Paul Everest, Gill Douce and the staff of Central Biological Services for assistance with in vivo studies. They also thank Drs John W. Foster and Paul N. Black for helpful discussions and critical reading of the manuscript.

Portions of the work presented here were funded by grants from the National Institutes of Health (grant no. GM4762801) and the University of South Alabama Research Council (to M.P.S.), the Albany Medical College Strategic Research Initiative (to C.D.R.), and the Medical Research Council of Canada (to B.B.F.). M. J.P. and G.D. would also like to thank the Wellcome Trust for supporting a Research Leave Fellowship for M. J.P.

\section{REFERENCES}

Babior, B. M. (1992). The respiratory burst oxidase. Adv Enzymol Relat Areas Mol Biol 65, 49-95.

Berlyn, M. K. B., Low, K. B., Rudd, K. E. \& Singer, M. (1996). Linkage map of Escherichia coli K-12, edition 9. In Escherichia coli and Salmonella: Cellular and Molecular Biology, 2nd edn, pp. 1715-1902. Edited by F. C. Neidhardt and others. Washington, DC: American Society for Microbiology.

Black, P. N. \& DiRusso, C. C. (1994). Molecular and biochemical analyses of fatty acid transport, metabolism, and gene regulation in Escherichia coli. Biochim Biophys Acta 1210, 123-145.

Brown, M. R. W. \& Williams, P. (1985). The influence of environment on envelope properties affecting survival of bacteria in infections. Annu Rev Microbiol 39, 527-556.

Cashel, M. Gentry, D. R., Hernandez, V. J. \& Vinella, D. (1996). The stringent response. In Escherichia coli and Salmonella: Cellular and Molecular Biology, 2nd edn, pp. 1458-1496. Edited by F. C. Neidhardt and others. Washington, DC: American Society for Microbiology.

Castilho, B. A., Olfson, P. \& Casadaban, M. J. (1984). Plasmid insertion mutagenesis and lac gene fusions with mini-Mu bacteriophage transposons. J Bacteriol 158, 488-495.
Chan, R. K., Botstein, D., Watanabe, T. \& Ogata, Y. (1972). Specialized transduction of tetracycline resistance by phage P22 in Salmonella typhimurium. II. Properties of a high transducing lysate. Virology 50, 883-898.

Cronan, J. E. \& Rock, C. O. (1996). Biosynthesis of membrane lipids. In Escherichia coli and Salmonella: Cellular and Molecular Biology, 2nd edn, pp. 612-636. Edited by F. C. Neidhardt and others. Washington, DC: American Society for Microbiology.

Davis, R. W., Botstein, D. \& Roth, J. R. (1980). Advanced Bacterial Genetics. Cold Spring Harbor, NY: Cold Spring Harbor Laboratory.

DiRusso, C. C. (1996). The role of long chain acyl-CoA esters in the regulation of gene expression and metabolism in Escherichia coli. In Frontiers in Bioactive Lipids, pp. 15-22. Edited by J. Y. Vanderhoek. New York: Plenum.

DiRusso, C. C. \& Nyström, T. (1998). The fats of Escherichia coli during infancy and old age: regulation by global regulators, alarmones and lipid intermediates. Mol Microbiol 27, 1-8.

DiRusso, C. C., Heimert, T. L. \& Metzger, A. K. (1992). Characterization of FadR, a global transcriptional regulator of fatty acid metabolism in Escherichia coli: interaction with the fadB promoter is prevented by long chain fatty acyl coenzyme As. $J$ Biol Chem 267, 8685-8691.

DiRusso, C. C., Heimert, T. L. \& Metzger, A. K. (1993). Regulation of transcription of genes required for fatty acid transport and fatty acid biosynthesis in Escherichia coli. Mol Microbiol 7, 311-322.

El-Khani, M. A. \& Stretton, R. J. (1981). Effect of growth medium on the lipid composition of log and stationary phase cultures of Salmonella typhimurium. Microbios 31, 161-169.

Fang, F. C., Libby, S. J., Buchmeier, N. A., Loewen, P. C., Switala, J., Harwood, J. \& Guiney, D. G. (1992). The alternative $\sigma$ factor KatF (RpoS) regulates Salmonella virulence. Proc Natl Acad Sci USA 89, 11978-11982.

Farewell, A., Diez, A. A., DiRusso, C. C. \& Nyström, T. (1996). Role of the Escherichia coli FadR regulator in stasis survival and growth phase-dependent expression of the uspA, fad, and $f a b$ genes. J Bacteriol 178, 6443-6450.

Finlay, B. B. \& Falkow, S. (1989). Salmonella as an intracellular parasite. Mol Microbiol 3, 1833-1841.

Foster, J. W. \& Spector, M. P. (1986). Phosphate-starvation regulon of Salmonella typhimurium. J Bacteriol 166, 666-669.

Foster, J. W. \& Spector, M. P. (1995). How Salmonella survive against the odds. Annu Rev Microbiol 49, 145-174.

Garcia del Portillo, F., Foster, J. W., Maguire, M. E. \& Finlay, B. B. (1992). Characterization of the micro-environment of Salmonella typhimurium-containing vacuoles within MDCK epithelial cells. Mol Microbiol 6, 3289-3297.

Gui, L. A., Sunnarborg, A. \& LaPorte, D. C. (1996). Regulated expression of a repressor protein: FadR activates iclR. J Bacteriol 178, 47044709 .

Harder, W. \& Dijkhuizen, L. (1983). Physiological responses to nutrient limitation. Annu Rev Microbiol 37, 1-23.

Hengge-Aronis, R. (1993). The role of $r p o S$ in early stationary phase gene regulation in Escherichia coli K12. In Starvation in Bacteria, pp. 171-200. Edited by S. Kjelleberg. New York: Plenum.

Hengge-Aronis, R. (1996). Regulation of gene expression during entry into stationary phase. In Escherichia coli and Salmonella: Cellular and Molecular Biology, 2nd edn, pp. 1497-1512. Edited by F. C. Neidhardt and others. Washington, DC: American Society for Microbiology. 
Hoiseth, S. K. \& Stocker, B. A. D. (1981). Aromatic-dependent Salmonella typhimurium are non-virulent and effective as live vaccines. Nature 291, 238-239.

Hughes, K. T. \& Roth, J. R. (1988). Transitory cis complementation: a method for providing transposition functions to defective transposons. Genetics 119, 9-12.

Huisman, G. W., Siegele, D. A., Zambrano, M. M. \& Kolter, R. (1996). Morphological and physiological changes during stationary phase. In Escherichia coli and Salmonella: Cellular and Molecular Biology, 2nd edn, pp. 1672-1682. Edited by F. C. Neidhardt and others. Washington, DC: American Society for Microbiology.

Jenkins, D. E., Schultz, J. E. \& Matin, A. (1988). Starvationinduced cross-protection against heat or $\mathrm{H}_{2} \mathrm{O}_{2}$ challenge in Escherichia coli. J Bacteriol 170, 3910-3914.

Klein, K. (1973). Acyl-CoA Debydrogenasen und ETF in Escherichia coli: Studien zum Fettsäureabbau. Doctoral Dissertation, Universität zu Köln.

Klein, K., Steinberg, R., Fiethen, B. \& Overath, P. (1971). Fatty acid degradation in Escherichia coli: an inducible system for the uptake of fatty acids and further characterization of old mutants. Eur J Biochem 19, 442-450.

Koch, A. L. (1971). The adaptive response of Escherichia coli to a feast and famine existence. Adv Microb Physiol 6, 147-217.

Lange, R. \& Hengge-Aronis, R. (1991). Identification of a central regulator of stationary-phase gene expression in Escherichia coli. Mol Microbiol 5, 49-59.

Loewen, P. C. \& Hengge-Aronis, R. (1994). The role of the sigma factor $\sigma^{\mathrm{S}}(\mathrm{KatF})$ in bacterial global regulation. Annu Rev Microbiol 48, 53-80.

McCann, M. P., Fraley, C. D. \& Matin, A. (1991). The putative $\sigma$ factor KatF has a central role in development of starvationmediated general resistance in Escherichia coli. J Bacteriol 173, 4188-4194.

McLeod, G. I. \& Spector, M. P. (1996). Starvation- and stationaryphase-induced resistance to the antimicrobial peptide polymyxin $\mathrm{B}$ in Salmonella typhimurium is $\operatorname{RpoS}\left(\sigma^{\mathrm{s}}\right)$ independent and occurs through both phoP-dependent and -independent pathways. J Bacteriol 178, 3683-3688.

Mahan, M. J., Tobias, J. W., Slauch, J. M., Hanna, P. C., Collier, J. R. \& Mekalanos, J. J. (1995). Antibiotic based selection for bacterial genes that are specifically induced during infection of a host. Proc Natl Acad Sci USA 92, 669-673.

Maloy, S. R. (1990). Experimental Techniques in Bacterial Genetics. Boston, MA: Jones \& Bartlett.

Matin, A. (1991). The molecular basis of carbon-starvationinduced general resistance in Escherichia coli. Mol Microbiol 5, 3-10.

Miller, J. H. (1972). Experiments in Molecular Genetics. Cold Spring Harbor, NY: Cold Spring Harbor Laboratory.

Miller, J. H. (1992). A Short Course in Bacterial Genetics: a Laboratory Manual and Handbook for Escherichia coli and Related Bacteria. Cold Spring Harbor, NY: Cold Spring Harbor Laboratory.

Moriarty, D. J. W. \& Bell, R. T. (1993). Bacterial growth and starvation in aquatic environments. In Starvation in Bacteria, pp. 25-53. Edited by S. Kjelleberg. New York: Plenum.

Mulvey, M. R. \& Loewen, P. C. (1989). Nucleotide sequence of katF of Escherichia coli suggests $\mathrm{KatF}$ protein is a novel $\sigma$ transcription factor. Nucleic Acids Res 17, 9979-9991.
Neidhardt, F. C., Bloch, P. L. \& Smith, D. F. (1974). Culture medium for enterobacteria. J Bacteriol 119, 736-747.

O'Neal, C. R., Gabriel, W. M., Turk, A. K., Libby, S. J., Fang, F. C. \& Spector, M. P. (1994). RpoS is necessary for both the positive and negative regulation of starvation survival genes during phosphate, carbon, and nitrogen starvation in Salmonella typhimurium. $J$ Bacteriol 176, 4610-4616.

Overath, P., Pauli, G. \& Schairer, H. U. (1969). Fatty acid degradation in Escherichia coli. An inducible acyl-CoA synthetase, the mapping of old mutants, and isolation of regulatory mutants. Eur J Biochem 7, 559-574.

Parks, C. L., Chang, L. S. \& Shenk, T. (1991). A polymerase chain reaction mediated by a single primer: cloning of genomic sequences adjacent to a serotonin receptor protein coding region. Nucleic Acids Res 19, 7155-7160.

Raman, N. \& DiRusso, C. C. (1995). Analysis of acyl coenzyme A binding to the transcription factor FadR and identification of amino acid residues required for ligand binding. J Biol Chem 270 , 1092-1097.

Rosenthal, A., Coutelle, O. \& Craxton, M. (1993). Large-scale production of DNA sequencing template by microtitre format PCR. Nucleic Acids Res 21, 173-174.

Roszak, D. B. \& Colwell, R. R. (1987). Survival strategies of bacteria in the natural environment. Microbiol Rev 51, 365-379.

Rudd, K. E., Bochner, B. R., Cashel, M. \& Roth, J. R. (1985). Mutations in the spoT gene of Salmonella typhimurium: effects on his operon expression. J Bacteriol 163, 534-542.

Saier, M. H., Ramseier, T. M. \& Reizer, J. (1996). Regulation of carbon utilization. In Escherichia coli and Salmonella: Cellular and Molecular Biology, 2nd edn, pp. 1325-1343. Edited by F. C. Neidhardt and others. Washington, DC: American Society for Microbiology.

Sanderson, K. E., Hessell, A., Liu, S.-L. \& Rudd, K. E. (1996). The genetic map of Salmonella typhimurium, edition VIII. In Escherichia coli and Salmonella: Cellular and Molecular Biology, 2nd edn, pp. 1903-1999. Edited by F. C. Neidhardt and others. Washington, DC: American Society for Microbiology.

Schultz, J. E., Latter, G. I. \& Matin, A. (1988). Differential regulation by cyclic AMP of starvation protein synthesis in Escherichia coli. J Bacteriol 170, 3903-3909.

Seymour, R. L., Mishra, P. V., Khan, M. A. \& Spector, M. P. (1996). Essential roles of core starvation-stress response loci in carbonstarvation-inducible cross-resistance and hydrogen peroxideinducible adaptive resistance to oxidative challenge in Salmonella typhimurium. Mol Microbiol 20, 497-505.

Spector, M. P. (1990). Gene expression in response to multiple nutrient-starvation conditions in Salmonella typhimurium. FEMS Microbiol Ecol 74, 175-184.

Spector, M. P. (1998). The starvation-stress response (SSR) of Salmonella. Adv Microb Pbysiol 40 233-279.

Spector, M. P. \& Cubitt, C. L. (1992). Starvation-inducible loci of Salmonella typhimurium: regulation and roles in starvation survival. Mol Microbiol 6, 1467-1476.

Spector, M. P. \& Foster, J. W. (1993). Starvation-stress response (SSR) of Salmonella typhimurium: gene expression and survival during nutrient starvation. In Starvation in Bacteria, pp. 201-224. Edited by S. Kjelleberg. New York: Plenum.

Spector, M. P., Aliabadi, Z., Gonzalez, T. \& Foster, J. W. (1986). Global control in Salmonella typhimurium: two-dimensional gel electrophoretic analysis of starvation-, anaerobiosis-, and heatshock-inducible proteins. J Bacteriol 168, 420-424. 
Spector, M. P., Park, Y. K., Tirgari, S., Gonzalez, T. \& Foster, J. W. (1988). Identification and characterization of starvation-regulated genetic loci in Salmonella typhimurium by using Mud-directed lacZ operon fusions. J Bacteriol 170, 345-351.

Tanaka, K., Takayanagi, Y., Fujita, N., Ishihama, A. \& Takahashi, H. (1993). Heterogeneity of the principal $\sigma$ factor in Escherichia coli: the $r p o S$ gene product, $\sigma^{38}$, is a second principal $\sigma$ factor of RNA polymerase in stationary-phase Escherichia coli. Proc Natl Acad Sci USA 90, 3511-3515.
Taylor, F. \& Cronan, J. E., Jr (1976). Selection and properties of Escherichia coli mutants defective in the synthesis of cyclopropane fatty acids. J Bacteriol 125, 518-523.

Valdivia, R H. \& Falkow, S. (1997). Probing bacterial gene expression within host cells. Trends Microbiol 5, 360-363.

Received 23 April 1998; revised 28 September 1998; accepted 7 October 1998. 